\title{
Molekulargenetische Untersuchungen zur Verbesserung der männlichen Fruchtbarkeit und Bekämpfung des Erbdefektes Hernia inguinalis/scrotalis in der Schweinezucht
}

\author{
Dissertation \\ zur Erlangung des Doktorgrades \\ der Fakultät für Agrarwissenschaften \\ der Georg-August-Universität Göttingen
}

\author{
vorgelegt von \\ Monique Germerodt \\ geboren in Eisenach
}

Göttingen, Februar 2009 
D 7

1. Referent: Prof. Dr. Dr. Bertram Brenig

2. Korreferent: Prof. Dr. Christoph Knorr

Tag der mündlichen Prüfung: 30.01.2009 



\section{Inhaltsverzeichnis}

Verzeichnis der Abkürzungen II

Verzeichnis der Tabellen IV

Verzeichnis der Abbildungen $\quad \mathrm{V}$

2.1 Die Künstliche Besamung (KB) beim Schwein 10

2.1.1 Historischer Überblick über die KB 10

2.1.2 Entwicklung und Stand der KB beim Schwein in Deutschland 11

2.1.3 Tierzüchterische Aspekte und der Einsatz der KB 12

2.1.4 Züchterisch vorteilhafte und nachteilige Genvarianten 18

2.2 Porcine Hernien $\quad 21$

2.2.1 Hernia inguinalis/scrotalis beim Schwein 21

2.2.2 Hodenabstieg (Descensus testis) 22

2.2.3 Störungen des Descensus testis 25

2.2.4 Vererbung, Häufigkeit und Bedeutung von Hernien 26

2.3 Fruchtbarkeit des Ebers $\quad 27$

$\begin{array}{ll}\text { 2.3.1 Spermatogenese } & 27\end{array}$

2.3.2 Kandidatengene für Fruchtbarkeitsparameter des Ebers 29

2.3.2.1 Das Phosphoglycerat Kinase 2 Gen (PGK2-Gen) 29

2.3.2.2 Das SRY (sex determining region Y)-box9 (SOX9-Gen) 30

2.4 Charakterisierung und Ausblick für das Projekt 31

2.4.1 FBF e.V. Forschungsprojekt „Defektgenkartierung beim Schwein“ 31

2.4.2 Identifikation merkmalsgekoppelter Genomregionen 32

2.4.3 Funktionelle Kandidatengene und weiterführende Verfahren 33

$\begin{array}{ll}\text { 2.4.4 Ausblick } & 37\end{array}$

3 ZUSAMMENFASSUNG $\quad 39$

4 SUMMARY $\quad 41$

5 LITERATURVERZEICHNIS $\quad 43$

6 PUBLIKATIONSLISTE UND KONGRESSBEITRÄGE

7 DANKSAGUNG 


\section{Verzeichnis der Abkürzungen}

$\begin{array}{ll}\text { AMH } & \text { Anti-Müller-Hormon } \\ \text { AS } & \text { Aminosäure } \\ \text { ATP } & \text { Adenosintriphosphat } \\ \text { BMBF } & \text { Bundesministerium für Bildung und Forschung } \\ \text { ca. } & \text { circa } \\ \text { CFH } & \text { Komplementfaktor H } \\ \text { CGRP } & \text { Calcitonin Gene-Related Peptide } \\ \text { cM } & \text { centi Morgan } \\ \text { DL } & \text { Deutsche Landrasse } \\ \text { DNA } & \text { Desoxyribonukleinsäure } \\ \text { E. coli } & \text { Escherichia coli } \\ \text { EGF } & \text { Epidermal-Growth Factor } \\ \text { ERN1 } & \text { Endoplasmic Reticulum-to-Nucleus Signaling 1/Inositol-Requiring } \\ \text { et al. } & \text { et alii (und andere) } \\ \text { FBF } & \text { Förderverein für Biotechnologieforschung e.V. } \\ \text { GFS } & \text { Genossenschaft zur Förderung der Schweinehaltung eG } \\ \text { GH } & \text { Growth hormone (Wachstumshormon) } \\ \text { GUSB } & \text { B-Glucuronidase } \\ \text { h2 } & \text { Heritabilität } \\ \text { HEXB } & \text { Hexosaminidase B } \\ \text { HOX } & \text { Homeobox } \\ \text { HYAL3 } & \text { Hyaluronidase 3 } \\ \text { ICSH } & \text { Interstitial Cell Stimulating Hormone } \\ \text { INSL3 } & \text { Insulin-like factor 3 } \\ \text { ISTS } & \text { Immotile Short-Tail Sperm } \\ \text { KB } & \text { Künstliche Besamung } \\ \text { LEP } & \text { Leptin } \\ \text { MHS } & \text { Malignes Hyperthermie-Syndrom } \\ \text { Mio } & \text { Millionen } \\ \text { OMIA } & \text { Online Mendelian Inheritance in Animals } \\ \text { PAC } & \text { P1-derived artificial chromosome } \\ \text { PCR } & \text { Polymerase Kettenreaktion } \\ \text { PGK1 } & \text { Phosphoglycerate Kinase 1 Gen } \\ \text { PGK2 } & \text { Phosphoglycerate Kinase 2 Gen } \\ \text { PRKAG3 } & \text { protein kinase AMP-activated gamma 3 non-catalytic subunit } \\ \text { PRKAR1A1 } & \text { cAMP-dependent regulatory type I alpha/tissue-specific } \\ & \text { extinguisher } \\ \text { PV } & \text { Processus vaginalis } \\ \text { QTL } & \text { Quantitative Trait Locus } \\ \text { RFLP } & \text { Restriktions-Fragment-Längenpolymorphismus } \\ \text { RYR1 } & \text { Ryanodin-Rezeptor 1 } \\ \text { SEPT4 } & \text { Septin 4 } \\ \text { SNP } & \text { Single Nucleotide Polymorphism } \\ \text { SOX9 } & \text { SRY (sex determining region Y) -box9 } \\ \text { SSC } & \text { Sus scrofa Chromosom } \\ \text { SZV } & \text { Schweinezuchtverband } \\ \text { Tab. } & \text { Tabelle } \\ & \end{array}$


TOMMI Targeted Oligonucleotide-Mediated Microsatellite Identification UCP1 Uncoupling Protein 1 Gen

VNTRs Variable Number of Tandem Repeats

WHO Weltgesundheitsorganisation

ZDS Zentralverband der Deutschen Schweineproduktion e.V. 


\section{Verzeichnis der Tabellen}

Tabelle 2-1:

Tabelle 2-2:

Tabelle 2-3:

Tabelle 2-4:

Tabelle 2-5:

Tabelle 2-6:

Tabelle 2-7:

Tabelle 2-8:

Tabelle 2-9:

Tabelle 2-10
Meilensteine der Künstlichen Besamung

Vor- und Nachteile der KB

(nach Busch und Waberski, 2007)

Richtwerte zur Beurteilung von Ejakulaten $\quad 7$

(nach Busch und Waberski, 2007)

Häufigkeiten kongenitaler Defekte beim Schwein

8

Verteilung der Häufigkeiten der Ferkel mit angeborenen Anomalien nach Rasse des Ebers über alle Geburtsjahrklassen (Beißner et.al, 2003)

Multiplikationsfaktoren für Anomalien im SZV Baden-Württemberg (Bullan, 2008)

Monogene Merkmale mit bekannter molekulargenetischer Ursache

(http://omia.angis.org.au/, Stand 10.12.2008)

Phasen des Descensus testis

Singlepoint-Analyse für SSC12 


\section{Verzeichnis der Abbildungen}

Abbildung 2-1: $\quad$ Entwicklung der Künstlichen Besamung in Deutschland (ZDS, 2008) 5

Abbildung 2-2: $\quad$ Descensus testis beim Schwein 17

Abbildung 2-3: $\quad$ Schematische Darstellung der Spermatogenese 22 (http://www.wissenschaft-online.de/abo/lexikon/biok/11007, Stand 10.12.2008)

Abbildung 2-4: $\quad$ Multipoint-Analyse für SSC 12 (Bornemann-Kolatzki, 2004)

Abbildung 2-5: $\quad$ Singlepoint-Analyse für SSC12 


\section{Einleitung}

Im Rahmen des vom Förderverein für Biotechnologieforschung (FBF e.V.) und dem Bundesministerium für Bildung und Forschung (BMBF) unterstützten Forschungsprojektes „Defektgenkartierung beim Schwein“ wird am Tierärztlichen Institut der Universität Göttingen der kongenitale Defekt Hernia inguinalis/scrotalis beim Schwein untersucht.

Das Auftreten kongenitaler Defekte in der Ferkel- sowie in der Zuchtschweineproduktion bedeutet für die betroffenen landwirtschaftlichen Betriebe ökonomische Einbußen.

Die Schwere des ökonomischen Verlustes ist abhängig von der Häufigkeit der Merkmalsträger in der Population und den anfallenden Totalverlusten bzw. Behandlungskosten, die durch den jeweiligen Defekt entstehen (Stigler, et al., 1991). Für das Auftreten von Hernia inguinalis/scrotalis sind sowohl genetische, als auch umweltbedingte Effekte verantwortlich. Allerdings ist der Erbgang dieses kongenitalen Defektes bis heute nicht zweifelsfrei aufgeklärt. Die geschätzten Heritabilitäten $\left(h^{2}\right)$ bewegen sich zwischen $h^{2}=0,21$ (Althoff, et al., 1988) und $h^{2}>0,6$ (Mikami and Fredeen, 1979;Thaller, et al., 1996). In einer am Tierärztlichen Institut durchgeführten Arbeit konnten mittels einer genomweiten Kopplungsanalyse chromosomale Regionen identifiziert werden, die mit dem Defekt Hernia inguinalis/scrotalis assoziiert sind (BornemannKolatzki, 2004). Ziel der vorliegenden Arbeit war es, eine dieser Regionen - das Sus Scrofa Chromosom (SSC) 12 - näher zu untersuchen und wenn möglich einzugrenzen. Basierend auf komparativen Genkarten wurden funktionelle Kandidatengene anhand des humanen Genoms ausgewählt und analysiert.

Neben der Bekämpfung von Erbdefekten sind auch Merkmale wie Tiergesundheit, so z.B. die Resistenz gegen Krankheitserreger, und die Fruchtbarkeit von großem tierzüchterischen und betriebswirtschaftlichen Interesse. In Anbetracht der Tatsache, dass die Künstliche Besamung (KB) ihren festen Platz in der heutigen Schweineproduktion hat, ist die Sicherstellung der Fruchtbarkeit der Besamungseber von großer Bedeutung. In der vorliegenden Arbeit wurden zudem zwei potentielle Kandidatengene für die Fruchtbarkeit des Ebers untersucht, um ihren Einfluss auf diverse Spermaparameter zu analysieren. 


\section{Literaturübersicht}

\subsection{Die Künstliche Besamung (KB) beim Schwein}

\subsubsection{Historischer Überblick über die KB}

Unter dem Begriff KB fasst man die Gewinnung, die Konservierung und Portionierung sowie die Übertragung von Sperma in den weiblichen Geschlechtstrakt zusammen. Die Anfänge der künstlichen Besamung liegen mehr als 300 Jahre zurück. Die Forschung und Weiterentwicklung auf diesem Gebiet ist von bedeutenden Entdeckungen in den darauf folgenden Jahren gekennzeichnet, welche in Tabelle 2-1 dargestellt sind.

Tabelle 2-1: Meilensteine der Künstlichen Besamung

\begin{tabular}{|c|c|c|c|}
\hline Beitrag & Wissenschaftler & Zeitraum & Quelle \\
\hline Entdeckung der „Samentierchen“ & $\begin{array}{l}\text { Ham und } \\
\text { Leeuwenhoek }\end{array}$ & 1677 & $\begin{array}{l}\text { (Schmitt, } \\
\text { 1950) }\end{array}$ \\
\hline erste KB beim Hund & Spallanzani & $\begin{array}{l}\text { Ende } 18 . \\
\text { Jahrhundert }\end{array}$ & $\begin{array}{l}\text { (Busch and } \\
\text { Waberski, } \\
\text { 2007) }\end{array}$ \\
\hline $\begin{array}{l}\text { erste Monographie „Die künstliche } \\
\text { Befruchtung bei Haustieren“ }\end{array}$ & Iwanow & 1912 & $\begin{array}{l}\text { (Busch and } \\
\text { Waberski, } \\
\text { 2007) }\end{array}$ \\
\hline $\begin{array}{l}\text { erste künstliche Scheide für } \\
\text { Bullenentsamung }\end{array}$ & Roemmele & 1926 & $\begin{array}{l}\text { (Busch and } \\
\text { Waberski, } \\
\text { 2007) }\end{array}$ \\
\hline Auffanggefäß für Ebersperma & McKenzie & 1931 & $\begin{array}{l}\text { (Busch and } \\
\text { Waberski, } \\
\text { 2007) }\end{array}$ \\
\hline $\begin{array}{l}\text { erste Besamungsgenossenschaft } \\
\text { (Insel Samsö, Dänemark) }\end{array}$ & Sörensen & 1936 & $\begin{array}{l}\text { (Geldermann, } \\
\text { 2005) }\end{array}$ \\
\hline $\begin{array}{l}\text { erste Deutsche Besamungsstation } \\
\text { (Pinneberg, Hamburg) }\end{array}$ & Götz und Rosenberger & 1942 & $\begin{array}{l}\text { (Geldermann, } \\
\text { 2005) }\end{array}$ \\
\hline $\begin{array}{l}\text { erfolgreiche } \\
\text { Langzeitkonservierung durch } \\
\text { Tiefgefrieren von Rindersperma }\end{array}$ & Polge und Mitarbeiter & 1949 & $\begin{array}{l}\text { (Busch and } \\
\text { Waberski, } \\
\text { 2007) }\end{array}$ \\
\hline
\end{tabular}

Seit dem Ende des zweiten Weltkrieges ist ein starker Anstieg der KB zu verzeichnen. Primärer Ansatzpunkt war, die Ausbreitung von Deckseuchen zu vermeiden. Ein weiterer Aspekt, der in den Forschungsmittelpunkt rückte, war 
die Konservierbarkeit des Spermas und die sich daraus ergebende Möglichkeit einer längeren Aufbewahrungszeit und des flächendeckenden Einsatzes des Spermas. Beim Rind ist die Herstellung von Tiefgefriersperma ein gut etabliertes Verfahren, mit dem Befruchtungsraten annähernd denen des Natursprunges erzielt werden. 1950 wurden bereits 20\% des Rinderbestandes in Deutschland mittels KB besamt. Im Jahr 2005 waren es 81,9\% des Gesamtbestandes. Die künstliche Besamung beim Pferd wurde zwischen 1930 und 1940 in Russland etabliert. 1985 wurden in Deutschland lediglich 1,3\% Stuten mittels KB besamt. Wohingegen derzeit ca. $80 \%$ des gesamten Stutenbestandes in Deutschland mit KB von Frischsperma besamt werden. Die Herstellung von Tiefgefriersperma erfolgt nur zu Exportzwecken, da bei der KB mit Frischsperma bessere Befruchtungsraten erzielt werden (Busch and Waberski, 2007). Beim Schwein wird weltweit die KB mit Frischsperma bevorzugt, da die Herstellung von Tiefgefriersperma sehr aufwendig ist und geringere Befruchtungsraten erzielt werden. Die Herstellung von Tiefgefriersperma wird nur für Exportzwecke angewendet und zur Erstellung von Genreserven züchterisch wertvoller Blutlinien. Die Genossenschaft zur Förderung der Schweinehaltung eG Ascheberg (GFS/Ascheberg) bietet ein Verfahren zur Herstellung von Tiefgefriersperma an und garantiert eine Befruchtungsfähigkeit über einen sehr langen Zeitraum. Die Befruchtungsraten haben sich im Vergleich zu früheren Jahren verbessert. Wird der Eisprung mit Hilfe von Ultraschalluntersuchungen zeitlich eingegrenzt und erfolgt die KB mit Tiefgefriersperma ca. 4-6 Stunden vor dem Eisprung intrauterin, sind die Befruchtungsergebnisse annähernd mit denen der KB mit Frischsperma vergleichbar (Riesenbeck, 2007).

\subsubsection{Entwicklung und Stand der KB beim Schwein in Deutschland}

In Deutschland hat sich die Künstliche Besamung beim Schwein im Vergleich zum Rind anfangs nur langsam entwickelt. Doch durch die Zunahme großer Schweinezucht- und Mastanlagen wurden die Weiterentwicklung und Verbesserung des Verfahrens gefördert. In den 90er Jahren stieg die KB beim Schwein rapide an (Abbildung 2-1). Im Jahr 2007 wurden in Deutschland 6831 Besamungseber in 21 Besamungsstationen gehalten. Allein 46,3\% dieser Eber 
gehörten der Rasse Pietrain an. Von ca. 2,4 Millionen (Mio.) gehaltenen Sauen im Jahr 2007 wurden über 90\% mittels KB besamt. 98,5\% der Besamungen wurden durch Eigenbestandsbesamer und 1,5\% von Tierärzten durchgeführt. Insgesamt wurden etwa 5,6 Mio. Doppelportionen Sperma im Jahr 2007 verkauft (ZDS, 2008).

Abbildung 2-1: Entwicklung der Künstlichen Besamung in Deutschland (ZDS, 2008).

\subsubsection{Tierzüchterische Aspekte und der Einsatz der KB}

Die Tierzucht hat zum Ziel, das Leistungsvermögen der produzierten Nachkommen zu verbessern und somit auch die ökonomischen Erträge der landwirtschaftlichen Produktion zu steigern. Neben der Leistungssteigerung sind auch Selektionsmerkmale wie Tiergesundheit und Fruchtbarkeit von großer ökonomischer Bedeutung. Um diese Zuchtziele zu erreichen, bedient sich die Tierzucht der Selektion und gezielten Anpaarung leistungsstarker Elterntiere (Busch and Waberski, 2007). Mit Hilfe der KB kann aufgrund der erhöhten Nachkommenzahl je Eber ein wesentlicher Zuchtfortschritt in kürzerer Zeit erzielt werden. Allerdings bringt die KB neben vielen Vorteilen auch nicht zu vernachlässigende Nachteile mit sich (Tabelle 2-2). 
Tabelle 2-2: Vor- und Nachteile der KB (Busch and Waberski, 2007)

\begin{tabular}{ll}
\hline Vorteile & Nachteile \\
\hline Vermeidung von Deckseuchen & Anzahl Vatertiere reduziert \\
$\begin{array}{l}\text { hohe Nachkommenzahl je Eber, } \\
\text { erhöhte Selektionsgrundlage }\end{array}$ & $\begin{array}{l}\text { Anstieg Inzuchtkoeffizient, somit } \\
\text { Erhöhung des Homozygotiegrades } \\
\text { stabile Basis für Zuchtwertschätzung }\end{array}$ \\
breites Spektrum passender Vererber & Verlust genetischer Variabilität \\
keine Produktionsausfälle für Landwirt & Verbreitung von Erbdefekten \\
bedingt durch eigene Deckeberhaltung & \\
Haltungskosteneinspaarungen & \\
umfassende Prüfung des Spermas der KB Eber & \\
\hline
\end{tabular}

Wie in Tabelle 2-2 erwähnt, ist ein großer Vorteil der KB, dass das Sperma einer eingehenden Untersuchung, sowohl auf Quantität als auch auf Qualität unterzogen wird, bevor es in der KB zum Einsatz kommt. Nach der hygienischen Samenentnahme und dem Abfiltrieren des Bulbourethraldrüsensekretes, werden verschiedene Spermaparameter mittels Mikroskop und photometrischen Messungen gemäß den Richtlinien der Weltgesundheitsorganisation (WHO) erhoben und ausgewertet. Optisch wird die Farbe und Konsistenz des Ejakulates bestimmt. Die Farbe des Ejakulates sollte milchig-weiß bis gelbweiß sein und es sollte eine wässrige bis rahmige Konsistenz aufweisen. Weiterhin werden das Gesamtvolumen, die Anzahl vorwärtsbeweglicher Spermien, die Spermienkonzentration und Gesamtmenge der Spermien pro Ejakulat, die Anzahl abnormer Spermien sowie der pH-Wert bestimmt. Die Richtwerte für diese Parameter sind in Tabelle 2-3 aufgelistet. 
Tabelle 2-3: Richtwerte zur Beurteilung von Ejakulaten (Busch and Waberski, 2007)

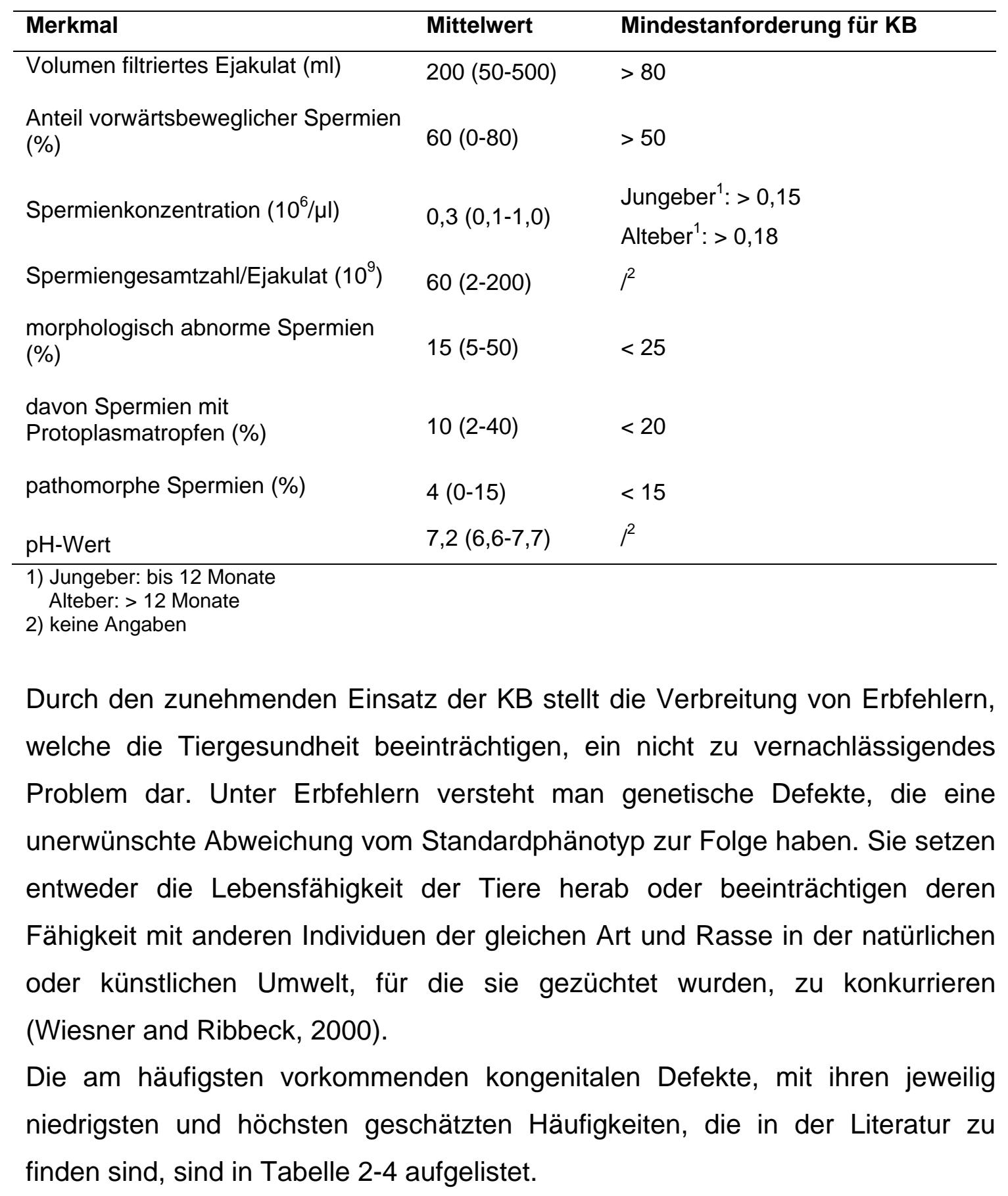


Tabelle 2-4: Häufigkeiten kongenitaler Defekte beim Schwein

\begin{tabular}{|c|c|c|}
\hline Defekt & Frequenz (\%) & Autoren \\
\hline $\begin{array}{l}\text { Leisten- und Hodensackbrüche (Hernia } \\
\text { inguinalis/scrotalis) }\end{array}$ & $0,30-1,00$ & $\begin{array}{l}\text { (Stigler, 1990;Matzke and } \\
\text { Averdunk, 1979) }\end{array}$ \\
\hline Nabelbrüche (Hernia umbilicalis) & $0,05-0,20$ & $\begin{array}{l}\text { (Stigler, 1990); (Foerster, } \\
\text { 1985) }\end{array}$ \\
\hline Verborgenhodigkeit (Kryptorchismus) & $0,01-1,32$ & $\begin{array}{l}\text { (Schwark, et al., 1970); } \\
\text { (Kobylka, et al., 1984) }\end{array}$ \\
\hline Afterlosigkeit (Atresia ani) & $0,09-0,45$ & $\begin{array}{l}\text { (Thaller, et al., 1996); } \\
\text { (Glodek, 1977) }\end{array}$ \\
\hline Zwitter (Hermaphroditismus) & $0,03-1,44$ & $\begin{array}{l}\text { (Stigler, et al., 1992); (Smidt, } \\
\text { 1962) }\end{array}$ \\
\hline Zittern (Myoclonia congenita) & $0,11-0,20$ & $\begin{array}{l}\text { (Stigler, et al., 1992), (Smidt, } \\
\text { 1972) }\end{array}$ \\
\hline $\begin{array}{l}\text { Spreizferkel (kongenitale myofibrilläre } \\
\text { Hypoplasie) }\end{array}$ & $0,20-21,2$ & $\begin{array}{l}\text { (Stigler, et al., 1992); (Maass } \\
\text { and Schulze, 1979) }\end{array}$ \\
\hline sonstige Missbildungen & $0,01-0,15$ & $\begin{array}{l}\text { (Samuels, 1993); (Thaller, et } \\
\text { al., 1996) }\end{array}$ \\
\hline
\end{tabular}

Neuere Studien wurden an einer Eberpopulation aus Bayern der Rassen Deutsche Landrasse (DL) und Pietrain durchgeführt. Hier wurden 47323 Würfe von 351 DL-Ebern und 1134 Pietrain-Ebern im Zeitraum von 1982 bis 2001 untersucht. Die nach einem linearen Modell errechneten Frequenzen der am häufigsten auftretenden kongenitalen Defekte sind in Tabelle 2-5 aufgelistet (Beißner, et al., 2003a). 
Tabelle 2-5: Verteilung der Häufigkeiten der Ferkel mit angeborenen Anomalien nach Rasse des Ebers über alle Geburtsjahrklassen (Beißner, et al., 2003a)

\begin{tabular}{lll}
\hline & \multicolumn{2}{c}{ Rasse } \\
\hline & DL & Pietrain \\
\cline { 2 - 3 } Anomalie & \multicolumn{2}{c}{ Häufigkeit (\%) } \\
Afterlosigkeit & 0,07 & 0,05 \\
Hodensackbruch & 0,32 & 0,55 \\
Nabelbruch & 0,04 & 0,04 \\
Kryptorchismus & 0,34 & 0,25 \\
Zwitter & 0,05 & 0,03 \\
sonstige Missbildungen & 0,10 & 0,08 \\
Zittern & 0,06 & 0,05 \\
Grätschen & 0,49 & 0,62 \\
\hline
\end{tabular}

In diesen Analysen wurde gezeigt, dass über die untersuchten Geburtsjahrgangsklassen der Eber von 1982 bis 2001, ein Rückgang der angeführten Anomalien zu beobachten ist. Ein starker Rückgang der Anomalie Afterlosigkeit ist bei beiden Rassen zu beobachten, bei DL-Ebern liegt dieser bei $72 \%$ und bei Ebern der Rasse Pietrain bei 58,3\%. Für den Defekt Hernia scrotalis konnte bei der Rasse DL ein Rückgang um ca. 70\% nachgewiesen werden, demgegenüber steht bei der Rasse Pietrain nur ein leichter Rückgang um ca. $24 \%$.

Im Rahmen der Umstellung der Anomalienberechnung wurden 51688 Würfe von 1750 Ebern der Besamungsgenossenschaft GFS/Ascheberg von der Universität Bonn (in Zusammenarbeit mit der GFS/Ascheberg) auf Anomalien geprüft und mittels eines linearen und eines threshold Modells die Häufigkeiten für die Erbfehler Hodensackbruch, Kryptorchismus, Afterlosigkeit, Nabelbruch, Zwitter, Grätschen, Zittern und sonstige Missbildungen ermittelt. Die Erbfehler Hodensackbruch, Binneneber, Grätscher und sonstige Missbildungen traten mit einer Häufigkeit von mehr als 1\% aller Würfe auf. Die Häufigkeit der anderen aufgeführten Anomalien hingegen war sehr gering (Buschbell, et al., 2007a). 
Erbdefekte bedeuten für die Schweineproduktion finanzielle Einbußen, aufgrund von Tierverlusten oder tierärztlichen Behandlungskosten. Die Höhe des Schadens ist abhängig von der Häufigkeit des auftretenden Defektes.

Seit Januar 1986 werden bei der Genehmigung der Besamungserlaubnis für KB-Eber die Ergebnisse der Anomalienprüfung einbezogen. Sie gestaltet sich je nach Besamungsstation aber unterschiedlich. Die Prüfung erfolgt durch Zuchtwertprüfstellen in Zusammenarbeit mit den Besamungsstationen.

Im Schweinezuchtverband (SZV) Baden-Württemberg werden bei der Erbfehlererfassung mindestens 30 Würfe je Eber auf Anomalien geprüft. Die einzelnen Defekte werden aufgrund ihres wirtschaftlichen Schadens mit einem Multiplikationsfaktor gewichtet. Die errechnete Punktzahl wird auf die Zahl der kontrollierten Würfe bezogen und damit der Erbfehlerindex berechnet. Überschreitet der Index den Wert von 1,5 wird der Eber gemerzt (Bullan, 2008).

Tabelle 2-6: Multiplikationsfaktoren für Anomalien im SZV Baden-Württemberg (Bullan, 2008)

\begin{tabular}{ll}
\hline Art des Erbfehlers & Multiplikator \\
\hline Leisten- und Hodensackbrüche & 4 \\
Afterlosigkeit & 10 \\
Binneneber & 5 \\
Nabelbruch & 4 \\
Zwitter & 5 \\
Grätscher & 1 \\
Zitterferkel & 1 \\
sonstige Missbildungen & 1 \\
\hline
\end{tabular}

Die Besamungsstation des Tierärztlichen Instituts Göttingen arbeitet mit einem Testbetrieb zusammen. Es werden je KB-Eber 30 Sauen belegt und die Nachkommen vom Betriebsleiter auf Anomalien untersucht. Es werden keine Anomalienkarten geführt. Bezogen auf die Anzahl der Nachkommen, die je Eber getestet wurden, wird der prozentuale Anteil an Anomalien berechnet. Liegt ein Eber für die Defekte Hernia inguinalis/scrotalis, Kryptorchismus oder Afterlosigkeit über 1\%, wird er von der Zucht ausgeschlossen. Die übrigen in 
Tabelle 2-6 aufgelisteten Anomalien werden weniger berücksichtigt, da sie einer starken Umweltkomponente unterliegen (Wemheuer, 2008).

Die GFS/Ascheberg hat in Zusammenarbeit mit der Universität Bonn ein sehr effizientes Verfahren zur Berechnung des Anomalienindexes der Besamungseber entwickelt. Vor der Umstellung des Verfahrens wurden von 120 Erzeugerringbetrieben und 300 Praxisbetrieben per FAX oder Sauenplaner aufgetretene Anomalien an die GFS/Ascheberg gemeldet. Für jede Anomalie wurden Strafpunkte vergeben, die abhängig vom wirtschaftlichen Schaden, den sie verursachen, gewichtet wurden. Die Punkte wurden summiert und zu einem gewichteten phänotypischen Erbfehlerindex zusammengefasst. Lag ein Endprodukteber über 80 und ein Vorstufeneber über 60 Punkte wurden diese gemerzt. Dies entsprach $10 \%$ aller auf Anomalien geprüften Eber. Nachteil dieses Verfahrens ist, dass weder Umwelteffekte noch Verwandtschaftsbeziehungen zwischen den Ebern berücksichtigt wurden. Wie unter 2.1.3 erwähnt, wurde in Zusammenarbeit mit der Universität Bonn ein Modell entwickelt, das sowohl die Daten der Erbfehlerermittlung, als auch die Verwandtschaftsbeziehungen und Umwelteffekte mit in die Berechnung des Anomalienindexes einbezieht. Diese neue Methode ist wesentlich zuverlässiger und ermöglicht außerdem, aufgrund der berücksichtigten Verwandtschaftsinformationen zwischen den Ebern, eine Einschätzung von Ebern, die noch keine großen Nachkommenzahlen aufweisen (Buschbell, et al., 2007b).

\subsubsection{Züchterisch vorteilhafte und nachteilige Genvarianten}

DNA-Varianten sind Positionen in einem DNA-Molekül, an der sich dieses von einem homologen Molekül unterscheidet. DNA-Varianten können Nukleotidsubstitutionen, -insertionen oder -deletionen sein. Sind sie auf eine Nukleotidposition zurückzuführen, nennt man sie Single Nucleotide Polymorphism (SNP). DNA-Varianten, die durch unterschiedlich häufige Sequenzwiederholungen gekennzeichnet sind, bezeichnet man als Variable Number of Tandem Repeats (VNTRs). DNA-Varianten lassen sich unabhängig von Alter, Geschlecht, Gewebe und Umwelteinflüssen darstellen und eignen sich somit als genetische Marker zur Charakterisierung von Populationen, 
Individuen und chromosomalen Regionen (Geldermann, 2005). Die Darstellung solcher DNA-Varianten ist mit Hilfe verschiedener molekularbiologischer Methoden möglich. Mit der Sequenzierung, der Polymerase-Kettenreaktion (PCR) und dem Restriktions-Fragment-Längenpolymorphismus (RFLP) seien nur einige Beispiele hierfür genannt. Durch den Nachweis solcher DNAVarianten können Tiere, die züchterisch vorteilhafte Genvarianten aufweisen, welche phänotypisch nicht unmittelbar erkennbar sind, entsprechend in der Zucht eingesetzt werden. Tiere, welche eine züchterisch nachteilige Genvariante tragen, können somit von der Zucht ausgeschlossen werden.

Es stehen zwei Möglichkeiten, diese Genvarianten nachzuweisen, zur Verfügung: 1) Der indirekte Gentest, auch als Kopplungsanalyse bezeichnet. Hier ist das Gen im Einzelnen nicht bekannt, aber chromosomal lokalisiert. Mikrosatellitenmarker, die in der betreffenden Genomregion liegen, werden verwendet, um den entsprechenden Genlocus nachzuweisen. Die Aussagekraft dieser Nachweismethode ist umso höher, je geringer die Rekombinationsrate zwischen Mikrosatellit und Genlocus ist, je mehr Mikrosatelliten in die Analyse einbezogen werden und je höher ihr Informationsgehalt ist. 2) Der direkte Gentest, hier ist das Gen bekannt, und die züchterisch relevanten, merkmalsverursachenden Genvarianten können auf DNA-Basis dargestellt werden (Geldermann, 2005).

Im Onlineregister der OMIA (Online Mendelian Inheritance in Animals) sind aktuell (Stand 10.12.2008) 215 Erbdefekte bzw. Merkmale für das Schwein verzeichnet. Davon sind 35 Merkmale, die einem monogenen Erbgang unterliegen und 13 davon deren molekulargenetische Ursache erforscht ist. Neben den, in Tabelle 2-7 aufgeführten Merkmalen, sind noch drei Merkmale, die für die Hautfarbe beim Schwein verantwortlich sind, molekulargenetisch beschrieben. Die genetische Ursache des Blutgruppensystems beim Schwein ist bekannt (Yamamoto and Yamamoto, 2001) und die Bildung von malignen Melanomen beim Sinclair-Schwein konnte molekulargenetisch identifiziert werden (Blangero, et al., 1996). 
Tabelle 2-7: Monogene Merkmale mit bekannter molekulargenetischer Ursache (http://omia.angis.org.au/, Stand 10.12.2008)

\begin{tabular}{|c|c|c|c|}
\hline Defekt/Merkmal & Genvarianten & Bedeutung & Autoren \\
\hline $\begin{array}{l}\text { MHS (Malignes } \\
\text { Hyperthermie Syndrom) }\end{array}$ & $\begin{array}{l}\text { Ryanodinrezeptor } 1 \\
\text { (RYR1); SNP mit } \\
\text { Aminosäurenaustausch } \\
\text { (AS) (Arg-615-Cys), } \\
\text { homozygot TT löst akute } \\
\text { Form aus, autosomal } \\
\text { rezessiv vererbt }\end{array}$ & $\begin{array}{l}\text { Stressanfälligkeit, Herz- } \\
\text { Kreislaufprobleme als } \\
\text { Folge einer Fehlregulation } \\
\text { im Calciumstoffwechsel } \\
\text { des Sarkoplasmatischen } \\
\text { Retikulums, Minderung } \\
\text { der Fleischqualität }\end{array}$ & $\begin{array}{l}\text { (Fujii, et al., } \\
\text { 1991) }\end{array}$ \\
\hline $\begin{array}{l}\text { Rendement Napole } \\
\text { (Kochschinken } \\
\text { Ausbeute) }\end{array}$ & $\begin{array}{l}\text { PRKAG3, SNP mit AS } \\
\text { (Arg-200G-In), autosomal } \\
\text { rezessiv vererbt }\end{array}$ & $\begin{array}{l}\text { erhöhter Muskel- } \\
\text { glycogengehalt und } \\
\text { geringerer pH-Wert 24h } \\
\text { post mortem }\end{array}$ & $\begin{array}{l}\text { (Leroy, et } \\
\text { al., 1990) }\end{array}$ \\
\hline $\begin{array}{l}\text { E.coli F18 Rezeptor } \\
\text { Resistenz }\end{array}$ & $\begin{array}{l}\text { E.coli Rezeptor F18/ } \alpha 1,2 \\
\text { Fucosyltransferase1, SNP } \\
\text { (Position AS-307 und AS- } \\
\text { 857), autosomal rezessiv } \\
\text { vererbt }\end{array}$ & $\begin{array}{l}\text { Fehlen von Rezeptoren } \\
\text { auf Darmschleimhaut } \\
\text { somit Resistenz gegen } \\
\text { Ödemkrankheit }\end{array}$ & $\begin{array}{l}\text { (Meijerink, } \\
\text { et al., } \\
\text { 1997); } \\
\text { (Vogeli, et } \\
\text { al., 1997) }\end{array}$ \\
\hline $\begin{array}{l}\text { Unvermögen der } \\
\text { zitterfreien } \\
\text { Wärmebildung }\end{array}$ & $\begin{array}{l}\text { Deletion von Exon } 3 \text { bis } 5 \\
\text { im Uncoupling Protein } 1 \\
\text { Gen (UCP1) }\end{array}$ & $\begin{array}{l}\text { Thermoregulation durch } \\
\text { Entkopplung oxidativer } \\
\text { Phosphorylierung der } \\
\text { ATP-Synthese gestört }\end{array}$ & $\begin{array}{l}\text { (Berg, et } \\
\text { al., 2006) }\end{array}$ \\
\hline $\begin{array}{l}\text { ISTS (Immotile Short-Tail } \\
\text { Sperm) }\end{array}$ & $\begin{array}{l}\text { Insertion eines } \\
\text { Retrotransposons im } \\
\text { Intron des KPL2-Gens, } \\
\text { autosomal rezessiv } \\
\text { vererbt }\end{array}$ & $\begin{array}{l}\text { Insertion verursacht } \\
\text { falsches Spleißen und } \\
\text { damit verbundene } \\
\text { Spermamissbildungen }\end{array}$ & $\begin{array}{l}\text { (Sironen, et } \\
\text { al., 2006) }\end{array}$ \\
\hline Hypercholesterolämie & $\begin{array}{l}\text { Low-Density-Lipoprotein } \\
\text { Rezeptor (LDLR), } \\
\text { autosomal rezessiv } \\
\text { vererbt, SNP mit AS } \\
\text { (Arg84Cys) }\end{array}$ & $\begin{array}{l}\text { erhöhtes Serum- und LDL- } \\
\text { Cholesterin }\end{array}$ & $\begin{array}{l}\text { (Hasler- } \\
\text { Rapacz, et } \\
\text { al., 1998) }\end{array}$ \\
\hline $\begin{array}{l}\text { Membranproliferative } \\
\text { Glomerulonephritis Typ II }\end{array}$ & $\begin{array}{l}\text { Komplementfaktor } \mathrm{H} \\
\text { (CFH), autosomal rezessiv } \\
\text { vererbt, SNP mit AS } \\
\text { (Ile1166Arg), weitere } \\
\text { Mutation beteiligt }\end{array}$ & $\begin{array}{l}\text { Komplement- } \\
\text { komponenten- } \\
\text { ablagerungen in der Niere }\end{array}$ & $\begin{array}{l}\text { (Hegasy, et } \\
\text { al., 2002) }\end{array}$ \\
\hline $\begin{array}{l}\text { Vitamin D abhängige } \\
\text { Rachitis Typ I }\end{array}$ & $\begin{array}{l}\text { Cytochrom P450C15 } \\
\text { (Hydroxyvitamin D3-1- } \\
\text { alpha hydroxylase), } \\
\text { autosomal rezessiv } \\
\text { vererbt, Deletion von } 173 \\
\text { bp oder } 357 \text { bp }\end{array}$ & $\begin{array}{l}\text { gestörte Synthese der } \\
\text { biologisch aktiven Form } \\
\text { des Vitamin } D \text {, das für die } \\
\text { Calcium-Homöostase } \\
\text { notwendig ist }\end{array}$ & $\begin{array}{l}\text { (Chavez, et } \\
\text { al., 2003) }\end{array}$ \\
\hline
\end{tabular}


Ein Großteil der züchterisch relevanten Merkmale unterliegt aber komplexen Erbgängen. Hier wurden mit Hilfe komparativer Genomkarten und Kopplungsanalysen QTL-Regionen (Quantitative Trait Loci) ermittelt, die mit Merkmalen gekoppelt sind, welche von großer Bedeutung für die Schweineproduktion sind. Aktuell (Stand 10.12.2008) sind 1831 QTLs, die mit 316 verschiedenen Merkmalen gekoppelt sind, in der PigQTL Datenbank verzeichnet (http://www.animalgenome.org/QTLdb/pig.html, Stand 10.12.2008). Gene und DNA-Varianten zu identifizieren, die an der Vererbung züchterisch relevanter Merkmale beteiligt sind, ist von großem ökonomischen Interesse in der Schweinezucht, da sich hieraus die Möglichkeit ergibt, spezifische Gentests zu entwickeln und die zur Zucht eingesetzten Tiere auf ihr genetisches Potential bezüglich der einzelnen Merkmale zu untersuchen. Für Produktionsmerkmale, wie Schlachtkörperzusammensetzung und Fleischqualität sind bereits eine Vielzahl an QTL-Regionen beschrieben. Ebenso für Fruchtbarkeitsmerkmale der Sau. Hingegen ist die Anzahl QTL-Regionen für Merkmale der männlichen Fruchtbarkeit marginal.

\subsection{Porcine Hernien}

Unter Hernien versteht man die Verlagerung von Organteilen aus einer natürlich ausgebildeten Körperhöhle durch eine angeborene oder traumatisch erworbene Bruchpforte der Körperhöhlenwand nach außen. Der Bruchinhalt fällt in eine vorgebildete Höhle vor oder in eine den Bruchsack darstellende Ausstülpung der Höhlenauskleidung. Eine Unterteilung der Hernien wird nach ihrer anatomischen Lokalisation durchgeführt (Wiesner and Ribbeck, 2000). Beim Schwein sind vor allem Leisten- und Hodensackbrüche, Bauchbrüche und Nabelbrüche von Bedeutung (siehe Tabelle 2-4).

\subsubsection{Hernia inguinalis/scrotalis beim Schwein}

Ein Leistenbruch entsteht aufgrund eines unphysiologisch weiten Leistenkanals oder eines anormal weiten Processus vaginalis (PV). Es fallen Eingeweide, zumeist Teile des Dünndarms und des großen Netzes, durch den 
inneren Leistenkanal in eine Nebenkammer der Bauchhöhle vor. Der Bruchsack bildet sich bei Leistenbrüchen im Leistenkanal.

Der Hodensackbruch geht aus dem Leistenbruch hervor. Hier fallen die Eingeweide allerdings bis in den Hodensack vor (Wiesner and Willer, 1974).

Leisten- und Hodensackbrüche können sowohl ein- als auch beidseitig auftreten. Es ist jedoch zu beobachten, dass bei männlichen Schweinen eine vermehrte linksseitige Hernienbildung auftritt (Stigler, 1990). Beide Brucharten sind angeborene, erbliche Defekte und die Tiere sind bereits seit der Geburt für diese Defekte prädisponiert (Dahme and Weiss, 1999;Waldmann and Wendt, 2001).

\subsubsection{Hodenabstieg (Descensus testis)}

Normale Embryonen sind zu Beginn ihrer Entwicklung potentiell bisexuell. Die Geschlechtsorgane entwickeln sich zunächst als indifferente Anlage, bevor sie sich mit Beginn der fetalen Entwicklungsphase zum männlichen oder weiblichen Geschlecht differenzieren. Die Keimdrüsenleiste entsteht durch Proliferation des Zölomephitels und Verdichtung des Mesenchyms medial an der Urnierenfalte. Die Keimdrüsenanlage ist von beträchtlicher Länge. Sie reicht vom Thorakal- bis zum Lumbalbereich. Der mittlere Abschnitt differenziert sich zur Keimdrüse. Aus dem kranialen Teil der Keimdrüse entsteht das kraniale Keimdrüsenband, aus dem kaudalen Teil das kaudale Keimdrüsenband, welches sich als Leistenband vom kaudalen Pol der Keimdrüse bis zum Leistenkanal erstreckt. Unter Einwirkung von Testosteron kommt es zur Rückbildung des kranialen Keimdrüsenbandes beim männlichen Tier. Das kaudale Keimdrüsenband entwickelt sich zum Leitband des Hoden, dem Gubernaculum testis (Schnorr and Kressin, 2006). Im Verlauf des Descensus testis (Abbildung 2-2) verlagern sich die Hoden aus ihrer ursprünglichen Lage nahe der Urnieren in den Hodensack, das Scrotum. Dies erfolgt beim Schwein ab dem 90. Tag der Trächtigkeit. Dieser Prozess ist sehr komplex und wird in der Literatur unter verschiedenen physiologischen Gesichtspunkten in mehrere Phasen unterteilt (Tabelle 2-8). 
Tabelle 2-8: Phasen des Descensus testis

\begin{tabular}{|c|c|c|}
\hline Autoren & Phasen & Charakteristika \\
\hline \multirow{2}{*}{$\begin{array}{l}\text { (Backhouse and } \\
\text { Butler, 1960); } \\
\text { (Hutson, 1985) }\end{array}$} & innere Phase & Migration der Hoden bis zum Leistenkanal \\
\hline & äußere Phase & $\begin{array}{l}\text { Passage der Hoden durch den Leistenkanal bis } \\
\text { in das Scrotum }\end{array}$ \\
\hline \multirow{3}{*}{$\begin{array}{l}\text { (Amann and } \\
\text { Veeramachaneni, } \\
\text { 2007) }\end{array}$} & $\begin{array}{l}\text { abdominale } \\
\text { Translokation }\end{array}$ & $\begin{array}{l}\text { Migration der Hoden aus der Bauchhöhle bis } \\
\text { zum inneren Inguinalring }\end{array}$ \\
\hline & $\begin{array}{l}\text { transinguinale } \\
\text { Migration }\end{array}$ & $\begin{array}{l}\text { Hoden und Nebenhoden treten durch die } \\
\text { Bauchdecke }\end{array}$ \\
\hline & $\begin{array}{l}\text { inguinoscrotale } \\
\text { Phase }\end{array}$ & $\begin{array}{l}\text { Migration der Hoden durch Leistenkanal bis in } \\
\text { das Scrotum }\end{array}$ \\
\hline \multirow[t]{5}{*}{$\begin{array}{l}\text { (Barteczko and } \\
\text { Jacob, 2000) }\end{array}$} & 1. Phase & $\begin{array}{l}\text { embryonale Entwicklung des Gubernaculum } \\
\text { testis }\end{array}$ \\
\hline & 2. Phase & $\begin{array}{l}\text { Abschnitte der Entstehung und Differenzierung } \\
\text { des Gubernaculum testis und des Processus } \\
\text { vaginalis }\end{array}$ \\
\hline & 3. Phase & $\begin{array}{l}\text { Migration der Hoden in der Bauchhöhle, } \\
\text { Anschwellen des Gubernaculum testis, } \\
\text { Entwicklung der Verbindung zwischen Hoden, } \\
\text { Nebenhoden und Gubernaculum testis }\end{array}$ \\
\hline & 4. Phase & $\begin{array}{l}\text { Entwicklung von Leistenkanal und äußerem } \\
\text { Leistenring, Migration der Hoden zum inneren } \\
\text { Leistenring }\end{array}$ \\
\hline & 5. Phase & $\begin{array}{l}\text { Rückbildung des Gubernaculum testis, } \\
\text { Inguinalkanalpassage der Hoden bis hinab in } \\
\text { das Scrotum }\end{array}$ \\
\hline
\end{tabular}

Treten im Verlauf dieses Prozesses Störungen auf, sodass der Leistenkanal unphysiologisch weit geöffnet bleibt und/oder der Processus vaginalis nicht vollständig verschlossen wird, kann dies zur Prädisposition für Hernia inguinalis/scrotalis führen (Dahme and Weiss, 1999;Waldmann and Wendt, 2001;Amann and Veeramachaneni, 2007). 
Abbildung 2-2: Descensus testis beim Schwein (Wensing, 1986).

(A) Entwicklung am Tag 65 post conceptionem (p.c.); (B) 75 Tage p.c.; (C) 8590 Tage p.c.; (D) bei der Geburt. 1. Hoden (Testis); 2. Nebenhoden (Epididymis); 3. parietales Blatt des Bauchfells (parietales Peritoneum); 4. innerer schiefer Bauchmuskel (Musculus obliquus internus abdominis); 5. äußerer schiefer Bauchmuskel (Musculus obliquus externus abdominis); 6. Scheidenhautfortsatz (Processus vaginalis); 7a. Gubernaculum testis; 7b. vaginaler Teil (pars vaginalis); 7c. infravaginaler Teil (pars infravaginalis); 8. Hodenheber (Musculus cremaster); 9. Fascia spermatica; 10. Tunica vaginalis. 


\subsubsection{Störungen des Descensus testis}

In der Literatur werden diverse Hypothesen über den detaillierten Ablauf und mögliche Einflussfaktoren auf den Descensus testis diskutiert. Es wird angenommen, dass eine intakte Steuerung über die HypothalamusHypophysen-Hoden-Achse von großer Bedeutung für den Descensus testis ist (Husmann and McPhaul, 1991;Spencer, et al., 1991). Weiterhin wird eine bihormonale Steuerung des Hodenabstieges postuliert, die von Androgenen und dem Mullerian-Inhibitor-Faktor kontrolliert wird (Hutson and Donahoe, 1986). Eine weitere Annahme ist, dass der Hodenabstieg neuronal über das Calcitonin Gene-Related Peptide (CGRP) kontrolliert wird. Durch die Maskulinisierung der Zellkerne und Nerven wird die CGRP-Sekretion erhöht, was zu rhythmischen Kontraktionen des Gubernaculum testis und somit zum Absteigen der Hoden in das Scrotum führt (Cain, et al., 1994a;Terada, et al., 1994;Heyns and Hutson, 1995). Ebenso spielt der Epidermal-Growth-Faktor (EGF) eine Rolle beim Hodenabstieg, da er entscheidend an der erhöhten Hyaluronsäureproduktion im Verlauf des Descensus testis beteiligt ist (Cain, et al., 1994b;Cain, et al., 1994c). Die Anreicherung der Hyaluronsäure findet im Gubernaculum testis statt (Heyns, et al., 1990), was dem EGF eine entscheidende Rolle beim Hodenabstieg einräumt. Eine weitere wichtige Rolle wird dem ansteigenden intraabdominalen Druck im Verlauf des Hodenabstieges zugeschrieben. Zu Beginn des Hodenabstieges senkt sich der offene PV in den Inguinalring $a b$ und überträgt den intraabdominalen Druck auf das Gubernaculum testis. Dieses wiederum befördert die Hoden durch den Inguinalkanal in das Scrotum (Levy and Husmann, 1995). Das Gubernaculum testis unterliegt im Verlauf der Embryonalentwicklung extremen Wachstumsund Rückbildungsprozessen, welche von diversen Hormonen reguliert werden. Im Wesentlichen wird das Anschwellen des Gubernaculum testis von den Hormonen Descendin und Oestradiol reguliert (Levy and Husmann, 1995). Beim Schwein steigt der Hoden entlang des vergrößerten Gubernaculum testis in das Scrotum ab (Heyns and Hutson, 1995;McMahon, et al., 1995). Eine Störung dieses Prozesses kann auf eine inadäquate Androgenwirkung zurückgeführt werden (Spencer, et al., 1991;Hutson and Donahoe, 1986; Heyns and Hutson, 1995;McMahon, et al., 1995). Levy und Husmann postulieren, 
dass Androgene verschiedene katabole Enzyme, wie die saure Phosphatase, und parakrine Faktoren beeinflussen, was eine Veränderung der viscoelastischen Eigenschaften des Gubernaculum testis zur Folge hat, da bei Nichtaktivität der katabolen Enzyme das Gubernaculum testis im Vergleich zum normalen Ablauf des Hodenabstieges vergrößert bleibt (Levy and Husmann, 1995). Somit nimmt das Gubernaculum testis eine Schlüsselfunktion im Verlauf des Hodenabstieges ein. Tanyel und Kollegen postulieren, dass aus dem Gewebe des Gubernaculum testis die glatten Muskelzellen um den PV entstehen, durch deren Kontraktion die Hoden durch den PV hinab in den Hodensack geleitet werden. Nach erfolgtem Hodenabstieg unterliegen diese Muskelzellen der Apoptose (programmierter Zelltod). Somit spielt die Apoptose eine entscheidende Rolle beim Verschluss des PV (Tanyel, 2004). Ist der Ablauf der Apoptose gestört, kann dies das Bestehen bleiben der glatten Muskelzellen zur Folge haben und das Verschließen des PV verhindern (Tanyel, et al., 1999).

\subsubsection{Vererbung, Häufigkeit und Bedeutung von Hernien}

Mit Hilfe gezielter Anpaarungen unter Nachkommen zweier Eber konnte bereits 1926 die Erblichkeit von Hernien nachgewiesen werden (Warwick, 1926). Der Erbgang ist bis heute nicht eindeutig geklärt und wird in der Literatur kontrovers diskutiert. Außerdem handelt es sich um eine oligofaktoriell bedingte Fehlbildung, da neben der genetischen Komponente auch Umwelteinwirkungen einen Einfluss auf die Entstehung von Hernien haben.

In der Literatur werden unterschiedliche Erbgangshypothesen diskutiert. Am wahrscheinlichsten ist ein oligogener oder polygener Erbgang. Allerdings ist bis heute der Vererbungsmodus von Hernia inguinalis/scrotalis nicht eindeutig geklärt. Heritabilitätsschätzungen wurden anhand verschiedener Kalkulationsmodelle und für verschiedene Rassen durchgeführt. Die niedrigsten Schätzwerte für die Heritabilität bei Tieren der Deutschen Landrasse (DL) wurden von Althoff mittels Varianzanalyse gemischter Modelle ermittelt $\left(h^{2}=\right.$ $0,022 \pm 0,006$ bis $0,035 \pm 0,007$ ) (Althoff, 1985). Die höchsten Heritabilitätsschätzwerte wurden in Untersuchungen von Mikami und Fredeen ermittelt $\left(h^{2}=0,65 \pm 0,06\right.$ bis $\left.0,86 \pm 0,16\right)$ (Mikami and Fredeen, 1979). In 
Untersuchungen von Beißner wurden mittels Vater-Sohn-Regression Heritabilitäten bei DL und Pietrain in Bayern ermittelt. Bei Nachkommen der Rasse DL wurden Heritabilitäten von $h^{2}=0,324 \pm 0,166$ und bei Nachkommen von Pietrain-Ebern Hertiabilitäten von $h^{2}=0,462 \pm 0,100$ ermittelt (Beißner, et al., 2003b).

In neueren Untersuchungen, die an 51688 Würfen von 1750 Ebern der Besamungsgenossenschaft GFS/Ascheberg von der Universität Bonn in Zusammenarbeit mit der GFS/Ascheberg durchgeführt wurden, konnten mittels eines linearen Modells für den Defekt Hernia inguinalis/scrotalis Heritabilitäten von $\mathrm{h}^{2}=0,14$ ermittelt werden (Buschbell, et al., 2007a).

Der Defekt Hernia inguinalis/scrotalis verursacht durch anfallende Behandlungskosten oder den akuten Totalausfall des betroffenen Tieres durch Inkarzeration beträchtliche wirtschaftliche Einbußen für die Schweineproduktion. Laut ZDS-Jahresbericht wurden 2007 ca. 2,8 Mio. Sauen in Deutschland gehalten, die durchschnittlich 23,5 Ferkel im Jahr gebären. Geht man von einer Häufigkeit von $1 \%$ des Defektes Hernia inguinalis/scrotalis aus, so sind ca. 658.500 Ferkel pro Jahr betroffen (ZDS, 2008).

\subsection{Fruchtbarkeit des Ebers}

\subsubsection{Spermatogenese}

Die Stammzellen der weiblichen und männlichen Geschlechtszellen bezeichnet man als Primordial- oder Urkeimzellen. Sie liegen zunächst extraembryonal im Dottersackepithel vor, von wo aus sie in die Keimdrüsenanlage einwandern. Beim weiblichen Geschlecht verbleiben die Urkeimzellen in der Rinde der Keimdrüsenanlage und entwickeln sich zu Ovogonien. Beim männlichen Geschlecht hingegen gelangen die Urkeimzellen in das Mark der Hodenanlage, wo sie sich in der folgenden fetalen und postnatalen Entwicklung zu Spermatogonien differenzieren. Erst mit dem Eintritt der Geschlechtsreife setzt die Weiterentwicklung zu morphologisch reifen Spermien ein. Diesen Prozess bezeichnet man als Spermatogenese. Dieser läuft als zyklischer Samenbildungsprozess in den Samenkanälchen (Tubuli seminiferi), die außen von einer bindegewebshaltigen Lamina propria begrenzt 
werden, ab. Lumenwärts an die Lamina propria schließt sich die Basalmembran an, welcher das Keimepithel aufliegt. Dem Keimepithel gehören die Zellgenerationen der Spermatogenese sowie ein zweiter Zelltypus, die somatischen Sertolizellen, die an der Spermatogenese beteiligt sind, an (Schnorr and Kressin, 2006). Die Sertolizellen bilden ursprünglich einen einschichtigen Epithelbelag, zwischen den sich die Ursamenzellen einlagern. Zwischen den Samenkanälchen befinden sich außerdem im Interstitium des Hodens die Leydig-Zwischenzellen. Sie bilden unter Einfluss des ICSH (Interstitial Cell Stimulating Hormone) das männliche Geschlechtshormon Testosteron, welches u.a. für die Ausbildung der primären und sekundären Geschlechtsmerkmale verantwortlich ist (Loeffler, 2002).

Im Verlauf der Spermatogenese (Abbildung 2-3) durchlaufen die Spermatogonien verschiedene Entwicklungsstadien. Über A- und BSpermatogonien entstehen durch die erste Reifeteilung primäre Spermatozyten, die sich wiederum nach der ersten meiotischen Teilung zu sekundären Spermatozyten entwickeln. Nach der zweiten Reifeteilung liegen Spermatide mit haploidem Chromosomensatz vor, die sich durch diverse Umbau- und Umformungsprozesse zu befruchtungsfähigen Spermien entwickeln (Loeffler, 2002). 
Abbildung 2-3: Schematische Darstellung der Spermatogenese (http://www.wissenschaft-online.de/abo/lexikon/biok/11007, Stand 10.12.2008).

\subsubsection{Kandidatengene für Fruchtbarkeitsparameter des Ebers}

\subsubsection{Das Phosphoglycerat Kinase 2 Gen (PGK2-Gen)}

Das autosomale PGK2-Gen ist auf SSC7q14-q15 lokalisiert (Chen, et al., 2004a) und wird im Verlauf der Spermatogenese stark exprimiert. Seine Transkription beginnt in den primären Spermatocyten und wird in den postmeiotischen Spermatiden beendet (McCarrey, et al., 2005). Die Phosphoglycerat Kinase katalysiert die reversible Konvertierung des 
1,3-Diphosphoglycerats zu 3-Phosphoglycerat. Im Verlauf der Glykolyse entsteht hierbei ein ATP-Molekül, welches Glukose oder Fruktose in Pyruvat umwandelt und den Stoffwechsel der Spermien während ihres Transportes durch die Nebenhoden reguliert (Salisbury, et al., 1977). Beim Menschen wurden zwei PGK-Gene identifiziert: Das X-chromosomal gekoppelte PGK1, welches ubiquitär exprimiert wird und das hodenspezifisch exprimierte PGK2 (Michelson, et al., 1983;McCarrey and Thomas, 1987). PGK1 wird im Hoden nur in der frühen Phase der Spermatogenese exprimiert und später von einem Isozym der Phophoglycerat-Kinase zu PGK2 modifiziert.

Das porcine PGK2-Gen besteht aus einem Exon und besitzt keine intronische Sequenz. Es ist 1251 bp lang, die für ein Protein von 417 Aminosäuren (AS) codieren (Chen, et al., 2004b). Die mRNA dieses Gens wird ausschließlich im Hoden exprimiert. Außerdem konnten Chen und Kollegen nachweisen, dass bei 10 Monate alten Ebern die Expression des PGK2-Gens im Vergleich zu erwachsenen Tieren wesentlich geringer ist (Chen, et al., 2004b). Von den zehn detektierten SNPs führen zwei zu einem Aminosäurenaustausch (SNPA: T-427C; SNPB: C-914-A), (SNPA: Ser ${ }^{102}$ zu Pro ${ }^{102}$; SNPB: Thr $^{264}$ zu Lys ${ }^{264}$ ). Für SNPB konnte für den Genotypen CC ein signifikant positiver Effekt auf das Spermavolumen von Pietrain-Ebern gezeigt werden. Eber, die den Genotyp CC aufwiesen, hatten ein um $49 \mathrm{ml}$ erhöhtes Ejakulatvolumen im Vergleich zu Ebern mit dem Genotyp AA.

\subsubsection{Das SRY (sex determining region Y)-box9 (SOX9-Gen)}

Das autosomale, porcine Sox9-Gen wurde auf SSC12p13-p14 lokalisiert (Ding, 2007). Es nimmt eine entscheidende Rolle bei der embryonalen Geschlechtsdifferenzierung ein und reguliert die Differenzierung der Sertolizellen. Es gehört zur Untergruppe E der Sox-Genfamilie. Sox9 bindet an die Promotorregion des Anti-Müller-Hormons $(\mathrm{AMH})$. AMH wird von den Sertolizellen ausgeschüttet und ist für die Rückbildung der Müllerschen Gänge im Verlauf der männlichen Geschlechtsentwicklung verantwortlich (De Santa Barbara, et al., 1998). Das porcine Sox9-Gen besitzt drei Exons und Introns. Die mRNA ist 1836 bp lang und codiert für 612 AS. Im Verlauf der Sequenzierung des Gens wurden im 5`untranslatierten Bereich eine 18 bp 
lange Insertion/Deletion und zwei polymorphe Mikrosatelliten identifiziert. Außerdem konnte gezeigt werden, dass die Deletion zu einer Erhöhung der Transkriptionsaktivität des Gens führt (Ding, 2007).

\subsection{Charakterisierung und Ausblick für das Projekt}

\subsubsection{FBF e.V. Forschungsprojekt „Defektgenkartierung beim Schwein"}

Das 1999 begonnene Projekt hat zum Ziel, geeignete Strategien zu entwickeln, um die genetische Ursache der für die Schweinezucht und - produktion wichtigsten Erbfehler (Afterlosigkeit, Hodensackbruch, Nabelbruch, Kryptorchismus, Zwitter und Grätschen) in Bezug auf den Einfluss einzelner Genorte aufzuklären. Im Folgenden sollen mit Hilfe vergleichender Chromosomenkarten potentielle Kandidatengene ermittelt werden, die auf kausale Mutationen hin untersucht werden sollen. Die am Tierärztlichen Institut durchgeführten Forschungsarbeiten konzentrieren sich auf den Defektkomplex Hernia inguinalis/scrotalis beim Schwein. Zunächst wurde ein Genomscan mit polymorphen DNA-Markern durchgeführt, um Genomregionen, die mit dem Phänotyp Hernia inguinalis/scrotalis assoziiert sind, zu identifizieren. Hierzu wurden 108 DNA-Marker an 71 Familien mit betroffenen Nachkommen typisiert. Es konnten fünf chromosomale Regionen mit dem Defekt assoziiert werden: Die porcinen Chromosomen 3, 6, 7, 12 und 15. Diese Regionen wurden mit 31 zusätzlichen Markern an insgesamt 84 Familien feinkartiert. An beiden Familienpedigrees wurden nichtparametrische Single- und MultipointKopplungsanalysen durchgeführt und für die Bereiche auf SSC 3, 6, 7 und 12 statistisch abgesichert. Von den insgesamt 139 typisierten Markern waren sechs SNPS: Das Wachstumshormon-Gen $(G H)$, das Ryanodin-Rezeptor-Gen (RYR1), das HOXA10-Gen (HOXA10), das Insulin-like-factor-3-Gen (INSL3 A und $B$ ) und das Leptin-Gen (LEP) (Bornemann-Kolatzki, 2004). Im weiteren Verlauf des Forschungsprojektes sollen die genannten Kandidatengene auf mögliche kausale Mutationen untersucht werden. Außerdem sollen die identifizierten Chromosomenregionen feinkartiert und anhand komparativer 
Genkarten weitere potentielle Kandidatengene ermittelt und untersucht werden. Die gewonnenen Erkenntnisse sollen in einer markergestützten Selektion zur Bekämpfung von Gendefekten in der Schweinezucht genutzt werden. Ziel ist es einen Gentest zu entwickeln, der es ermöglicht, Tiere, die den Defekt Hernia inguinalis/scrotalis vererben, von der Zucht auszuschließen.

\subsubsection{Identifikation merkmalsgekoppelter Genomregionen}

Die Kopplungsanalyse stellt ein geeignetes Verfahren zur Lokalisation bzw. Identifikation von Genen oder Genomregionen dar, die mit einem bestimmten Defekt/Merkmal assoziiert sind. Diese Methode findet insbesondere ihre Anwendung bei monogenen Erbkrankheiten oder bei der Identifikation von Hauptgenen einer komplexen Erbkrankheit. Die Kopplungsanalyse bedient sich der Tatsache, dass ein genetischer Marker in der Nähe des gesuchten Gens oder Genortes liegt und innerhalb einer Familie gemeinsam mit diesem vererbt wird. Liegen keine oder nur ungenügende Informationen zur Ätiologie der Krankheit vor, nutzt man die Durchmusterung des gesamten Genoms mit Hilfe vieler gleichmäßig verteilter DNA-Marker, um eine Kopplung zwischen Marker und Genort zu identifizieren. Liegen Informationen zu funktionellen Zusammenhängen zwischen Genen oder Genomregionen und zur phänotypischen Ausprägung des Merkmals vor, nutzt man die Kandidatengenanalyse. Deren Ziel ist, die Beteiligung des Kandidatengens an der Ausprägung des Krankheitsbildes nachzuweisen und die Schätzung des zugrunde gelegten genetischen Modells einschließlich der Quantifizierung des Einflusses auf die Krankheit (Allelhäufigkeit, Penetranz) (Clerget-Darpoux and Bonaiti-Pellie, 1992; Bickeböller and Fischer, 2007). Die Kopplungsanalyse basiert auf der genetischen Rekombination. Für genetisch komplexe Erkrankungen eignet sich vor allem die nichtparametrische Kopplungsanalyse, da das zugrunde liegende genetische Modell, also der Erbgang, nicht oder nur teilweise bekannt ist.

Die Assoziationsanalyse wird genutzt, um mittels Kopplungsanalysen identifizierte Kandidatengenregionen weiter einzugrenzen oder Kandidatengene direkt zu analysieren und die merkmalsassoziierten Genvarianten zu identifizieren. Beim genomweiten Ansatz werden Marker, die über das gesamte 
Genom verteilt sind, auf ihren Zusammenhang mit dem Merkmal untersucht. Dieser Ansatz konnte erst in den letzten Jahren durch die Entwicklung von Hochdurchsatzgenotypisierungsverfahren realisiert werden. Eine gesicherte statistische Assoziation ist gegeben, wenn eine Genvariante ursächlich dem Krankheitsbild zugeordnet werden konnte oder eine Genvariante sich im linkage disequilibrium, also im Kopplungsungleichgewicht, befindet (Bickeböller and Fischer, 2007).

\subsubsection{Funktionelle Kandidatengene und weiterführende Verfahren}

Aufgrund der unter Absatz 2.2.3 beschriebenen Einflussfaktoren auf den Descensus testis wurden in der ersten Phase des Forschungsprojektes „Defektgenkartierung beim Schwein“ mögliche Kandidatengene molekulargenetisch charakterisiert und mittels Kopplungsanalyse ihre Assoziation zum Defekt Hernia inguinalis/scrotalis ermittelt. Das INSL3, welches in den Leydig-Zellen der sich entwickelnden Hoden gebildet wird und das Wachstum der mesenchymalen Zellen des Gubernaculum testis stimuliert (Adham, et al., 1993), wurde als Kandidatengen für kongenitale Anomalien des Hodenabstieges in Betracht gezogen. Das porcine INSL3 wurde auf SSC2q12q13 lokalisiert (Rettenberger, et al., 1994) und liegt somit nicht in einer der in der genomweiten Kopplungsanalyse assoziierten Genomregionen (BornemannKolatzki, 2004). Bei Mäusen wurde festgestellt, dass bei Tieren, welche die Mutationen im INSL3 zeigen, beiderseitiger Kryptorchismus vorliegt sowie das Gubernaculum testis abnormal entwickelt ist (Zimmermann, et al., 1999;Nef and Parada, 1999). Knorr und Kollegen identifizierten zwei SNPs (G-224-A; A-164C) im Promotorbereich des Gens. Nach Untersuchungen an betroffenen Vollund Halbgeschwisterpopulationen wurde INSL3 allerdings als Kandidatengen in der untersuchten Population ausgeschlossen (Knorr, et al., 2004). Ein weiteres untersuchtes Gen ist das HOXA10, welches generell eine wichtige Rolle bei der Embryonalentwicklung einnimmt. Außerdem wurde an „Knock out“ Mäusen gezeigt, dass sich das Gubernaculum testis unphysiologisch entwickelt und Kryptorchismus auftritt (Satokata, et al., 1995;Branford, et al., 2000). Nach molekularbiologischer Charakterisierung und Kopplungsanalyse wurde jedoch auch das HOXA10 als funktionelles Kandidatengen ausgeschlossen 
(Uibeleisen, 2001). Es wurden außerdem SNPs im LEP (Stratil, et al., 1997) und im RYR1 (Brem and Brenig, 1992) untersucht. LEP wurde nach der Kopplungsanalyse als Kandidatengen ausgeschlossen, wohingegen RYR1 in einer Chromosomenregion lokalisiert ist, die mit dem Defekt assoziiert ist (Bornemann-Kolatzki, 2004). Weitere untersuchte Gene sind das Hexosaminidase B-Gen (HEXB), das Hyaluronidase-Gen (HYAL3) und das Calcitonin Gen-related Peptid (CGRP). Auch diese Gene wurden aufgrund ihrer chromosomalen Lokalisation und der nicht vorhandenen Merkmalskopplung als funktionelle Kandidatengene ausgeschlossen (Mueller, et al., 2003); (Gatphayak, et al., 2003;Knorr, et al., 2002). Das Glucuronidase-Gen (GUSB) konnte nach chromosomaler Lokalisation auf SSC3p14-p16 sowohl als positionelles wie funktionelles Kandidatengen eingestuft werden (Beck, et al., 2002). Im Folgenden wurden SNP-Analysen durchgeführt und die detektierten SNPs an einer Halbgeschwisterpopulation untersucht. Die Ergebnisse zeigten, dass GUSB in der untersuchten Population als Kandidatengen auszuschließen ist (Beck, et al., 2006). Die genomweite Kopplungsanalyse ergab für SSC12 die höchsten NPL-Werte (detaillierte Übersicht: (Bornemann-Kolatzki, 2004). Es wurden drei Kandidatengene aufgrund komparativer Genkarten als funktionelle Kandidatengene, das Protein Kinase cAMP-dependent regulatory type I alpha/Tissue-specific Extinguisher (PRKAR1A1), das Endoplasmic Reticulumto-Nucleus Signaling 1/Inositol-Requiring Gen (ERN1) und das Septin4-Gen (SEPT4), für das Merkmal Hernia inguinalis/scrotalis und das SOX9-Gen für die Fruchtbarkeit beim Eber untersucht. Das porcine PGK2-Gen wurde ebenfalls als Kandidatengen für die Fruchtbarkeit des Ebers analysiert, ist aber in der im genomweiten Markerscan assoziierten Region des SSC7 lokalisiert. Die im Rahmen der vorliegenden Arbeit durchgeführten molekulargenetischen Analysen sind in den Publikationen (Beuermann, et al., 2008; Germerodt, et al., 2008; Germerodt, et al., 2009; Knorr, et al., 2009) vorgestellt.

Nachfolgend sind die Ergebnisse der von Dr. Bornemann (Bornemann-Kolatzki, 2004) durchgeführten Typisierungen und der erweiterten Typisierungen der vorliegenden Arbeit, vergleichend dargestellt. 
QuickTime $^{\mathrm{TM}}$ and a

decompressor

are needed to see this picture.

Abbildung 2-4: Multipoint-Analyse für SSC 12 (Bornemann-Kolatzki, 2004).

Tabelle 2-9: Multipoint-Analyse für SSC 12 


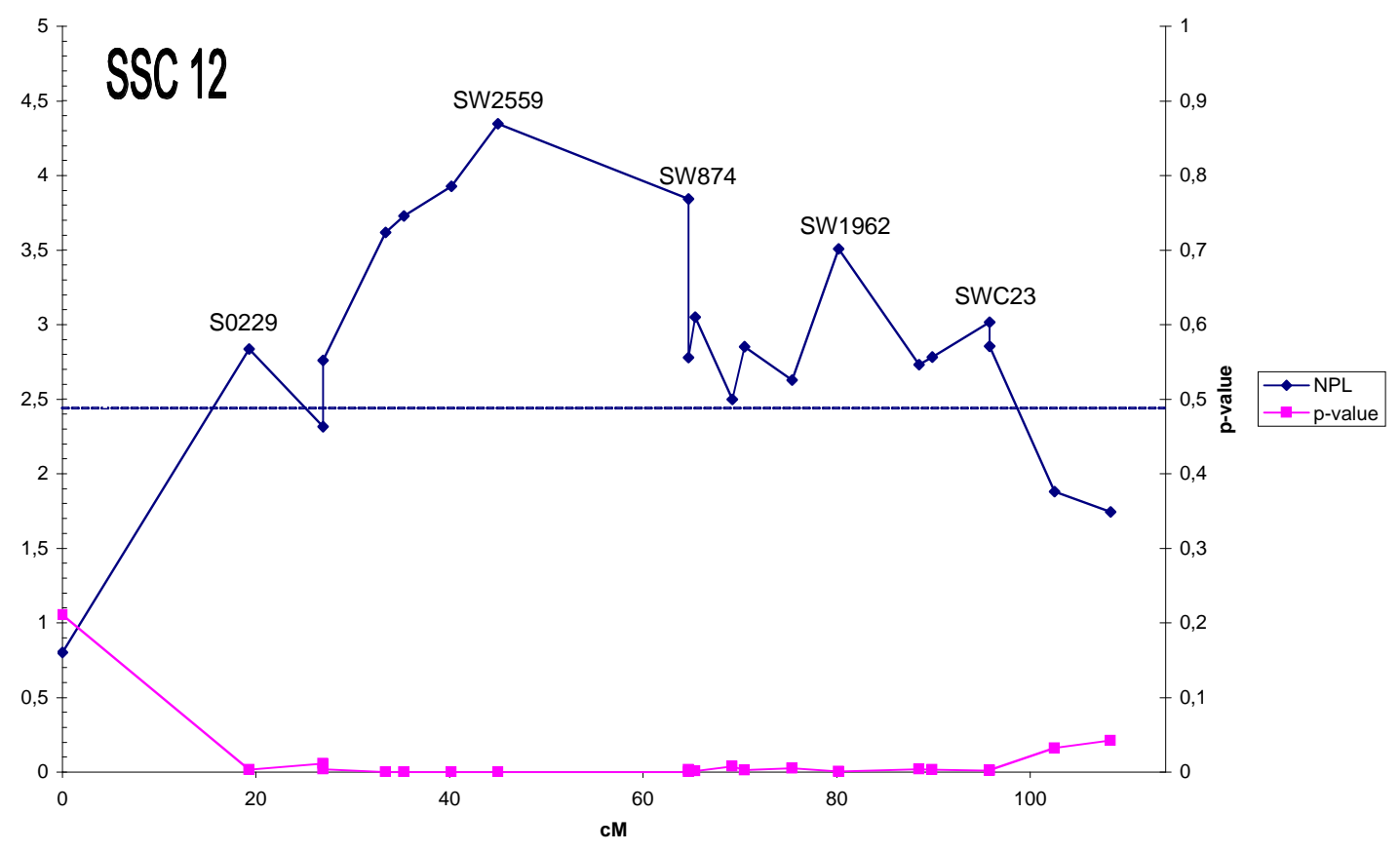

Abbildung 2-5: Singlepoint-Analyse für SSC12

Auf SSC 12 stiegen nach weiterer Feinkartierung und Typisierung weiterer Marker am Pedigree (Pedigree Beschreibung siehe Bornemann Kolatzki, 2004) die NPL-Werte im Chromosomenbereich zwischen 19,3 cM (S0229) und 85,8 cM (SWC23) weiter deutlich an. Der NPL-Wert für den Marker SW2559 zeigte Werte von über 4 bei einer Irrtumswahrscheinlichkeit von $p=0,00014$

Tabelle 2-10: Singlepoint-Analyse für SSC12

\begin{tabular}{|l|r|l|r|}
\hline Marker & Position MARC (cM) & Marker & Position MARC (cM) \\
\hline SW2490 & 0,0 & S0904 & 69,2 \\
\hline S0229 & 19,3 & SW168 & 70,5 \\
\hline S0891 & 26,9 & SWR1802 & 75,4 \\
\hline INS/DEL & & S0090 & 80,2 \\
\hline SW957 & 33,4 & SW1962 & 88,5 \\
\hline S0905 & 35,2 & S0147 & 89,9 \\
\hline SW1307 & 40,2 & S0106 & 95,8 \\
\hline GH & 45,0 & SWC23 & 95,8 \\
\hline SW2559 & 64,7 & LOX12A & 102,5 \\
\hline SW874 & 64,7 & SW605 & 108,3 \\
\hline S0902 & 65,3 & SWR1021 & 113,1 \\
\hline
\end{tabular}




\subsubsection{Ausblick}

Zusammenfassend lässt sich feststellen, dass mit Hilfe von Kopplungsund Assoziationsstudien sowie Kandidatengenanalysen Genomregionen, DNAMarker und Gene identifiziert werden konnten, die mit dem Defekt Hernia inguinalis/scrotalis assoziiert sind und somit dazu beitragen, die Ursachen für eine Prädisposition für Hernien aufzuklären. In unterschiedlichen Studien wurden verschiedene Genomregionen in unterschiedlichen Populationen mit dem Defekt assoziiert (Bornemann-Kolatzki, 2004;Grindflek, et al., 2006), was auf ein komplexes Krankheitsbild, das von diversen Genen, Gen-GenInteraktionen und Gen-Umwelt-Interaktionen beeinflusst wird, schließen lässt. Aus diesem Grund wird allein mit einem Kandidatengenansatz die komplexe Problematik des Defektes Hernia inguinalis/scrotalis nicht vollständig aufgeklärt werden können und somit sind weitere molekulargenetische Analysen notwendig.

Zum Beispiel kann mit Hilfe von DNA-Microarrays die Genexpression in unterschiedlichen Zelltypen verglichen werden, was zur Funktionsuntersuchung verschiedener Genomregionen genutzt werden kann. Außerdem lassen sich DNA-Varianten durch die allelspezifische Hybridisierung, die eine SNPIdentifikation ermöglicht, darstellen. Protein-Arrays ermöglichen die Analyse der Proteinexpression und der Interaktion zwischen Proteinen. Sie ermöglichen es, physiologische und pathophysiologische Prozesse molekularer Mechanismen zu analysieren und finden ihre Anwendung bei der Krankheitsdiagnostik und der Entwicklung therapeutischer Marker (Geldermann, 2005). Mit der Kombination aus genomweiter Kopplungsanalyse (QTL-Analyse) und Microarry-Analyse können bisher noch nicht bekannte Kandidatengene identifiziert werden, was einen bedeutenden Schritt für die funktionellen Analysen Genotyp-phänotypischer Beziehungen darstellt (Wayne and McIntyre, 2002). Neben den erwähnten Methoden und der Verwendung von Mikrosatelliten als DNA-Marker zur Identifizierung merkmalsgekoppelter Genomregionen, ist die Entwicklung von Mikrosatelliten eine verbreitete Methode. In der vorliegenden Arbeit wurden mit der targeted oligonucleotidemediated microsatellite identification (TOMMI) Methode (Chen, et al., 2005) aus Klonen, die aus einer PAC (P1-derived artificial chromosome) Genbank isoliert 
wurden und potentielle Kandidatengene für den Defekt Hernia inguinalis/scrotalis enthalten, Mikrosatelliten detektiert. Diese wurden an betroffenen Halbgeschwisterpopulationen untersucht. Es wurde mit Hilfe statistischer Auswertungen die Kopplung der Mikrosatelliten zum Merkmal Hernia inguinalis/scrotalis getestet. Auf diese Weise ist es möglich, eine Assoziation des Kandidatengens festzustellen bevor man mit der Sequenz- und SNP-Analyse des Gens beginnt. Des Weiteren wurden die detektierten Mikrosatelliten zur Feinkartierung der merkmalsassoziierten Genomregionen genutzt.

Die vorgestellten Methoden und Techniken, die sich aus innen ableiten, sind daher besonders für die Aufklärung der Vererbung komplexer Erkrankungen geeignet. 


\section{Zusammenfassung}

Die Künstliche Besamung $(\mathrm{KB})$ ist eine stark verbreitete, äußerst effiziente Reproduktionsbiotechnologie in der Schweinezucht. Etwa 90\% des gesamten Zuchtsauenbestandes in Deutschland wurden 2007 mittels KB besamt. Der zunehmende Einsatz der KB und die damit verbundene hohe Nachkommenzahl jedes einzelnen Ebers erfordert allerdings ein wirkungsvolles Programm zur Bekämpfung von Erbdefekten. Des Weiteren muss sichergestellt werden, dass das eingesetzte Sperma von gleich bleibend sehr guter Qualität ist. Folglich können nur Eber zur KB eingesetzt werden, die eine sehr gute Befruchtungsfähigkeit aufweisen.

Der kongenitale Defekt Hernia inguinalis/scrotalis beim Schwein tritt mit einer Häufigkeit von ca. 1-3\% in den Schweinepopulationen auf und wird mit einer Heritabilität von $h^{2}=0,02$ bis $h^{2}=0,86$ vererbt. Ausgehend von einer am Tierärztlichen Institut durchgeführten genomweiten Kopplungsanalyse bei der Genomregionen, die mit dem Defekt assoziiert sind, identifiziert wurden, wurden in der vorliegenden Arbeit drei weitere Kandidatengene auf dem porcinen Chromosom 12 untersucht. In zwei der drei Gene konnte mittels der targeted oligonucleotide mediated microsatellite identification (TOMMI) Methode jeweils ein polymorpher Mikrosatellit isoliert werden. Diese wurden an einer Population betroffener Familien typisiert und mit dem Programm Allegro ausgewertet. Es konnte eine signifikante Kopplung eines Mikrosatelliten mit dem Defekt Hernia inguinalis/scrotalis nachgewiesen werden.

Im zweiten Teil der Arbeit wurden zwei Kandidatengene, die eine potentielle Rolle bei der Ausprägung der Fruchtbarkeit des Ebers spielen, an einer Population von 204 Besamungsebern untersucht. Diese Proben wurden von FBF-Mitgliedsbetrieben zur Verfügung gestellt. Das porcine PGK2-Gen ist in die Prozesse der Spermatogenese involviert. In einer kürzlich am Tierärztlichen Institut durchgeführten Dissertation wurden zehn Mutationen in diesem Gen identifiziert. Zwei dieser Mutationen haben einen Aminosäurenaustausch zur Folge. Eine dieser Mutationen hat einen signifikant positiven Effekt auf das Spermavolumen. Diese Ergebnisse konnten in der vorliegenden Arbeit, an dem zugrunde liegenden Untersuchungsmaterial nicht bestätigt werden. Es wurde aber in der untersuchten Population ein signifikanter Effekt auf die 
Spermamotilität nachgewiesen. Das zweite Gen, das porcine Sox9, ist an der Geschlechtsdifferenzierung und der Differenzierung der Sertolizellen beteiligt. In diesem Gen konnten eine Insertion/Deletion von 18 bp Länge sowie zwei polymorphe Mikrosatelliten detektiert werden. Die 204 Besamungseber wurden auf die Insertion/Deletion hin untersucht und die Mikrosatellitentypisierung für alle Tiere durchgeführt. Es wurde ein signifikanter Einfluss des Sox9-Gens auf die Merkmale Spermamotilität und Spermavolumen nachgewiesen. 


\section{Summary}

Artificial insemination (Al) is a very common and efficient reproduction method in pig breeding. About $90 \%$ of all breeding sows in Germany were inseminate by artificial insemination in 2007. The increasing implementation of $\mathrm{Al}$ and the resulting high number of progeny per boar requires a stringent control to avoid the dispersion of congenital defects. Furthermore, sperm used for Al must have a constant high level of quality. Consequently, only boars with excellent fertilization traits are used for Al.

The frequency of the congenital defect Hernia inguinalis/scrotalis in pigs is about 1 to $3 \%$. The estimated heritabilities range from 0.02 to 0.86 .

At the Institute of Veterinary Medicine a genome wide markerscan was performed to identify chromosomal regions associated with Hernia inguinalis/scrotalis. Based on these results three candidate genes on porcine chromosome 12 were analysed further. In two of the three genes a polymorphic microsatellite was detected with the targeted oligonucleotide-mediated microsatellite identification (TOMMI) method. The microsatellites were typed in a popultion of effected families. The statistical calculations were done with the program Allegro. A significant linkage between one microsatellite and the congenital defect Hernia inguinalis/scrotalis was detected.

In the second part of this thesis two candidate genes were analysed which play an important role in reproduction traits in boars. The samples were provided by cooperation partners of the Förderverein für Biotechnologieforschung e.V. (FBF).

The porcine Phosphoglycerate Kinase 2 Gen (PGK2) gene is involved in spermatogenesis. Ten mutations were detected in a previous study. Two of these SNPs lead to an aminoacid substitution. One of these mutations was shown to have a significant positive influence on sperm volume in Al boars. However, these results could not be confirmed in this study. But we were able to detect a significant effect on sperm motility in the examined population. SRY (sex determining region Y)-box9 SOX9 is involved in the sex and sertoli cell differentiation. Within the SOX9 gene an $18 \mathrm{bp}$ insertion/deletion and two polymorphic microsatellites were identified. A population of 204 Al boars was 
analysed for these three markers. Significant effects on sperm motility and sperm volume were detected. 


\section{Literaturverzeichnis}

ADHAM, I.M., BURKHARDT, E., BENAHMED, M. und ENGEL, W.: Cloning of a cDNA for a novel insulin-like peptide of the testicular Leydig cells. J Biol Chem 268 (1993) 26668-72.

ALTHOFF, W.: Zur erblichen Abhängigkeit verschiedener Geburtsfehler beim Schwein. Dissertation, Rheinische Friedrich-Wilhelm-Universität Bonn (1985).

ALTHOFF, W., MAYER, M., RICHTER, L. und SIMON, D.: Zur erblichen Abhängigkeit der Geburtsfehler Brüche und Binnenhodigkeit beim Schwein. Züchtungskunde 60 (1988) 319-329.

AMANN, R.P. und VEERAMACHANENI, D.N.: Cryptorchidism in common eutherian mammals. Reproduction 133 (2007) 541-61.

BACKHOUSE, K.M. und BUTLER, H.: The gubernaculum testis of the pig (Sus scrofa). J Anat 94 (1960) 107-20.

BARTECZKO, K.J. und JACOB, M.I.: The Testicular Descent in Human. Origin, Development and Fate of the Gubernaculum Hunteri, Processus Vaginalis Peritonei and Gonadal Ligaments. Adv. Anat. Embryol. Cell. Biol. 156 (2000) 1-98.

BECK, J., BORNEMANN-KOLATZKI, K., KNORR, C., TAEUBERT, H. und BRENIG, B.: Molecular characterization and exclusion of porcine GUSB as a candidate gene for congenital hernia inguinalis/scrotalis. BMC Vet Res 2 (2006) 14.

BECK, J., KNORR, C., HABERMANN, F., FRIES, R. und BRENIG, B.: Assignment of the beta-glucuronidase (GUSB) gene to porcine chromosome SSC3p16-->p14 by FISH and confirmation by hybrid panel analyses. Cytogenet Genome Res 97 (2002) 277G.

BEIßNER, B., HAMANN, $H$. und DISTL, O.: Analyse der genetischen Parameter für kongenitale Anomalien bei den Schweinerassen Deutsche Landrasse und Pietrain in Bayern. Züchtungskunde 75 (2003a) 214-225.

BEIßNER, B., HAMANN, H. und DISTL, O.: Prävalenzen von kongenitalen Anomalien bei den Schweinerassen Deutsche Landrasse und Pietrain in Bayern. Züchtungskunde 75 (2003b) 101-114.

BERG, F., GUSTAFSON, U. und ANDERSSON, L.: The uncoupling protein 1 gene (UCP1) is disrupted in the pig lineage: a genetic explanation for poor thermoregulation in piglets. PLoS Genet 2 (2006) e129.

BEUERMANN, C., GERMERODT, M., BECK, J., BRENIG, B. und KNORR, C.: Chromosomal assignment of eight porcine genes involved in apoptosis. Anim Genet 39 (2008) 330-1.

BICKEBÖLLER, H. und FISCHER, C.: Einführung in die Genetische Epidemiologie. Springer Verlag, Berlin (2007).

BLANGERO, J., TISSOT, R.G., BEATTIE, C.W. und AMOSS, M.S., JR.: Genetic determinants of cutaneous malignant melanoma in Sinclair swine. Br J Cancer 73 (1996) 667-71.

BORNEMANN-KOLATZKI, K.: Dürchführung eines Genomscans mit polymorphen DNA-Markern und Genomic Mismatch Scanning (GMS) bei Sus scrofa zur Detektion Hernia inguinalis/scrotalis assoziierter Genomregionen. Dissertation, Tierärztliche Hochschule Hannover (2004). 
BRANFORD, W.W., BENSON, G.V., MA, L., MAAS, R.L. und POTTER, S.S.: Characterization of Hoxa-10/Hoxa-11 transheterozygotes reveals functional redundancy and regulatory interactions. Dev Biol 224 (2000) 373-87.

BREM, G. und BRENIG, B.: Molekulare Genotyp-Diagnostik des Malignen Hyperthermie-Syndrom zur effizienten Zucht stressresistenter Schweine. Wien. Tierärztl. Mschr. 79 (1992) 301-305.

BULLAN, G.: Persönliche Mitteilung (08.10.2008).

BUSCH, W. und WABERSKI, U.D.: Lehrbuch der künstlichen Besamung bei Haus- und Nutztieren. Schattauer Verlag, Stuttgart, 1. Auflage (2007).

BUSCHBELL, H., JONAS, E., WIESE, M. und THOLEN, E.: Untersuchung der genetischen Fundierung von Erbfehlern beim Schwein: Vergleich von linearen und threshold Modellen. Vortragstagung der DGfZ und GfT Stuttgart-Hohenheim (2007a).

BUSCHBELL, H., THOLEN, E. und WIESE, M.: Neue Zuchtwertschätzung für Erbfehler. TopGenetik, GFS (2007b) 18-19.

CAIN, M.P., KRAMER, S.A., TINDALL, D.J. und HUSMANN, D.A.: Alterations in maternal epidermal growth factor (EGF) effect testicular descent and epididymal development. Urology 43 (1994a) 375-8.

CAIN, M.P., KRAMER, S.A., TINDALL, D.J. und HUSMANN, D.A.: Epidermal growth factor reverses antiandrogen induced cryptorchidism and epididymal development. J Urol 152 (1994b) 770-3.

CAIN, M.P., KRAMER, S.A., TINDALL, D.J. und HUSMANN, D.A.: Expression of androgen receptor protein within the lumbar spinal cord during ontologic development and following antiandrogen induced cryptorchidism. J Urol 152 (1994c) 766-9.

CHAVEZ, L.S., SERDA, R., CHOE, S., DAVIDI, L., HARMEYER, J. und OMDAHL, J.L.: Molecular basis for pseudo vitamin D-deficiency rickets in the Hannover pig. J Nutr Biochem 14 (2003) 378-85.

CHEN, K., KNORR, C., MOSER, G., GATPHAYAK, K. und BRENIG, B.: Molecular characterization of the porcine testis-specific phosphoglycerate kinase 2 (PGK2) gene and its association with male fertility. Mamm Genome 15 (2004a) 996-1006.

CHEN, K.F., BECK, J., HUANG, L.S., KNORR, C. und BRENIG, B.: Assignment of the phosphoglycerate kinase 2 (PGK2) gene to porcine chromosome 7q14-q15 by fluorescence in situ hybridization and by analysis of somatic cell and radiation hybrid panels. Anim Genet 35 (2004b) 71-2.

CHEN, K., KNORR, C., BORNEMANN-KOLATZKI, K., REN, J., HUANG, L., ROHRER, G.A. und BRENIG, B.: Targeted oligonucleotide-mediated microsatellite identification (TOMMI) from large-insert library clones. BMC Genet 6 (2005) 54.

CLERGET-DARPOUX, F. und BONAITI-PELLIE, C.: Strategies based on marker information for the study of human diseases. Ann Hum Genet 56 (1992) 145-53.

DAHME, E. und WEISS, E.: Grundriss der speziellen pathologischen Anatomie der Haustiere. Enke Verlag, Stuttgart, 5. Auflage (1999).

DE SANTA BARBARA, P., BONNEAUD, N., BOIZET, B., DESCLOZEAUX, M., MONIOT, B., SUDBECK, P., SCHERER, G., POULAT, F. und BERTA, $P$.: Direct interaction of SRY-related protein SOX9 and steroidogenic 
factor 1 regulates transcription of the human anti-Mullerian hormone gene. Mol Cell Biol 18 (1998) 6653-65.

DING, N.: Deciphering the genetics of pig complex traits through QTL mapping and positional candidate cloning. Dissertation, Georg-August-Universität Göttingen (2007).

DU, F.X., MATHIALAGAN, N., DYER, C.J., GROSZ, M.D., MESSER, L.A., CLUTTER, T., WANG, T., LOHUIS, M.M. und BYATT, J.C.: Mapping genes affecting scrotal hernia condition in domestic pigs. J Anim. Sci. 82 (2004) Suppl. 1453

FOERSTER, M.: Untersuchungen zur Vererbung von Anomalien beim Schwein und zur Beeinflussung der Wurfgröße. Diplomarbeit, Fachhochschule Triesdorf (1985).

FUJII, J., OTSU, K., ZORZATO, F., de LEON, S., KHANNA, V.K., WEILER, J.E., O'BRIEN, P.J. und MacLENNAN, D.H.: Identification of a mutation in porcine ryanodine receptor associated with malignant hyperthermia. Science 253 (1991) 448-51.

GATPHAYAK, K., KNORR, C., HABERMANN, F., FRIES, R. und BRENIG, B.: Assignment of the porcine hyaluronidase-3 (HYAL3) gene to SSC13-$>$ q21 by FISH and confirmation by hybrid panel analyses. Cytogenet Genome Res 101 (2003) 178.

GELDERMANN, H.: Tier-Biotechnologie. Eugen Ulmer Verlag, Stuttgart, 1. Auflage (2005).

GERMERODT, M., BEUERMANN, C., ROHRER, G.A., SNELLING, W.M., BRENIG, B. und KNORR, C.: Characterization and linkage mapping of 15 porcine STS markers to fine-map chromosomal regions associated with hernia inguinalis/scrotalis. Anim Genet 39 (2008) 671-2.

GERMERODT, M., MOSER, G., R., C., DING, N., HUANG, L., XING, Y., PACH, S., BRENIG, B. und KNORR, C.: Associations of PGK2 and SOX9 variants with reproduction performance in Artificial Insemination (AI) boars. Anim Reprod Sci in Bearbeitung (2009).

GLODEK, P.: Bedeutung und Möglichkeit der Bekämpfung von Erbfehlern in der Schweinezucht. Der Tierzüchter 29 (1977) 518-21.

GRINDFLEK, E., MOE, M., TÄUBERT, H., SIMIANER, H., LIEN, S. und MOEN, T.: Genome-wide linkage analysis of inguinal hernia in pigs using affected sib pairs. BMC Genet 7 (2006) 25.

HASLER-RAPACZ, J., ELLEGREN, H., FRIDOLFSSON, A.K., KIRKPATRICK, B., KIRK, S., ANDERSSON, L. und RAPACZ, J.: Identification of a mutation in the low density lipoprotein receptor gene associated with recessive familial hypercholesterolemia in swine. Am J Med Genet 76 (1998) 379-86.

HEGASY, G.A., MANUELIAN, T., HOGASEN, K., JANSEN, J.H. und ZIPFEL, P.F.: The molecular basis for hereditary porcine membranoproliferative glomerulonephritis type II: point mutations in the factor $\mathrm{H}$ coding sequence block protein secretion. Am J Pathol 161 (2002) 2027-34.

HEYNS, C.F. und HUTSON, J.M.: Historical review of theories on testicular descent. J Urol 153 (1995) 754-67.

HEYNS, C.F., HUMAN, H.J., WERELY, C.J. und DE KLERK, D.P.: The glycosaminoglycans of the gubernaculum during testicular descent in the fetus. J Urol 143 (1990) 612-7. 
HTTP://OMIA.ANGIS.ORG.AU/: (Stand 10.12.2008).

HTTP://WWW.ANIMALGENOME.ORG/QTLDB/PIG.HTML: (Stand 10.12.2008). HTTP://MWW.WISSENSCHAFT-ONLINE.DE/ABO/LEXIKON/BIOK/11007: (Stand 10.12.2008).

HUSMANN, D.A. und McPHAUL, M.J.: Time-specific androgen blockade with flutamide inhibits testicular descent in the rat. Endocrinology 129 (1991) 1409-16.

HUTSON, J.M.: A biphasic model for the hormonal control of testicular descent. Lancet 2 (1985) 419-21.

HUTSON, J.M. und DONAHOE, P.K.: The hormonal control of testicular descent. Endocr Rev 7 (1986) 270-83.

KNORR, C., KOLLERS, S., FRIES, R. und BRENIG, B.: Assignment of the CALC-A/alpha-CGRP gene (CALCA) to porcine chromosome SSC2p13-$>$ p11 by fluorescence in situ hybridization and by analysis of somatic cell and radiation hybrid panels. Cytogenet Genome Res 97 (2002) 140F.

KNORR, C., TÄUBERT, H., PETERS, U. und BRENIG, B.: Characterization of two SNPs (single nucleotide polymorphisms) in the porcine INSL3 gene and their exclusion as a common genetic basis of hernia inguinalis in pigs. Biochem Genet 42 (2004) 9-11.

KNORR, C., BORNEMANN-KOLATZKI, K., BECK, J., GERMERODT, M., HARLIZIUS, B., TÄUBERT, H. und BRENIG, B.: Approaching inguinal and scrotal hernias in pigs. Anim Genet in Bearbeitung (2009).

KOBYLKA, V., CERNY, M. und HAJKOVA, J.: Inherited abnormalities and defects in pedigreed herds of pigs in the Czech Republic 19791983. Veterinarstvi 34 (1984) 351-352.

LE ROY, P., NAVEAU, J., ELSEN J.M. und SELLIER, P.: Evidence for a new major gene influencing meat quality in pigs. Genet Res 55 (1990) 33-40.

LEVY, J.B. und HUSMANN, D.A.: The hormonal control of testicular descent. J Androl 16 (1995) 459-463.

LOEFFLER, K.: Anatomie und Physiologie der Haustiere. UTB, Eugen Ulmer Verlag, Stuttgart (2002) 10. aktualisierte und korrigierte Auflage (2002).

MAASS, P. und SCHULZE, U.J.: Zur genetischen Disposition des angeborenen Beinspreizens bei Saugferkeln. Mh. Vet.-Med. 34 (1979) 20-21.

MATZKE, P. und AVERDUNK, U.G.: Binneneber züchterisch bekämpfen. Top Agrar 5 (1979) 21.

McCARREY, J.R. und THOMAS, K.: Human testis-specific PGK gene lacks introns and possesses characteristics of a processed gene. Nature 326 (1987) 501-5.

MCCARREY, J.R., GEYER, C.B. und YOSHIOKA, H.: Epigenetic regulation of testis-specific gene expression. Ann N Y Acad Sci 1061 (2005) 226-42.

McMAHON, D.R., KRAMER, S.A. und HUSMANN, D.A.: Antiandrogen induced cryptorchidism in the pig is associated with failed gubernacular regression and epididymal malformations. J Urol 154 (1995) 553-7.

MEIJERINK, E., FRIES, R., VOGELI, P., MASABANDA, J., WIGGER, G., STRICKER, C., NEUENSCHWANDER, S., BERTSCHINGER, H.U. und STRANZINGER, G.: Two alpha(1,2) fucosyltransferase genes on porcine chromosome $6 q 11$ are closely linked to the blood group inhibitor (S) and Escherichia coli F18 receptor (ECF18R) loci. Mamm Genome 8 (1997) 736-41. 
MICHELSON, A.M., MARKHAM, A.F. und ORKIN, S.H.: Isolation and DNA sequence of a full-length cDNA clone for human $X$ chromosomeencoded phosphoglycerate kinase. Proc Natl Acad Sci U S A 80 (1983) 472-6.

MIKAMI, H. und FREDEEN, U.H.T.: A genetic study of cryptorchidism and scrotal hernia in pigs. Can. J. Genet. 61 (1979) 128-131.

MUELLER, A., KNORR, C., HABERMANN, F., SLANCHEV, K., ZWILLING, D., FRIES, R. und BRENIG, B.: Assignment of the beta-Nacetylhexosaminidase gene (HEXB) to porcine chromosome SSC2q21-$>$ q22 by fluorescence in situ hybridization and by analysis of somatic cell and radiation hybrid panels. Cytogenet Genome Res 101 (2003) 178.

NEF, S. und PARADA, L.F.: Cryptorchidism in mice mutant for Insl3. Nat Genet 22 (1999) 295-9.

RETTENBERGER, G., BURKHARDT, E., ADHAM, I.M., ENGEL, W., FRIES, R., KLETT, C. und HAMEISTER, H.: Assignment of the Leydig insulinlike hormone to porcine chromosome $2 q 12-q 13$ by somatic cell hybrid analysis and fluorescence in situ hybridization. Mamm Genome 5 (1994) 307-9.

RIESENBECK, A.: Besamungsmanagement Tiefgefriersperma- Export und Genreserve.

TopGenetik,GFSwww.gfstopgenetik.de/download.php?file $=p$

df_files/fachbeitraege/tk_sperma.pdf (2007) (abgerufen am 14.10.2008).

SALISBUTRY, G.W., HART, R.G. und LODGE, J.R.: The spermatozoan genome and fertility. Am J Obstet Gynecol 128 (1977) 342-50.

SAMUELS, J.: Die Beziehung zwischen Wurfgröße und Anomalienfrequenz beim Schwein. Dissertation, Georg-August-Universität Göttingen (1993).

SATOKATA, I., BENSON, G. und MAAS, R.: Sexually dimorphic sterility phenotypes in Hoxa10-deficient mice. Nature 374 (1995) 460-3.

SCHMITT, J.: Literaturstudie über die Biologie des Sperma. Dissertation, Justus-Liebig-Hochschule zu Giessen (1950).

SCHNORR, B. und KRESSIN, M.: Embryologie der Haustiere. Enke Verlag, Stuttgart 5. neu bearbeitete Auflage (2006).

SCHWARK, H.J., SENG, W. und DÖRING, W.: Zum Auftreten von Erbschäden und Leistungsdepression in Inzuchtwürfen des Schweins. Tierzucht 24 (1970) 256-257.

SIRONEN, A., THOMSEN, B., ANDERSSON, M., AHOLA, V. und VILKKI, J.: An intronic insertion in KPL2 results in aberrant splicing and causes the immotile short-tail sperm defect in the pig. Proc Natl Acad Sci U S A 103 (2006) 5006-11.

SMIDT, D.: Einige Beobachtungen über das Vorkommen von Zwittern beim Schwein. Zuchthygiene 6 (1962) 371-373.

SMIDT, W.J.: Congenital defects in pigs. Proc. VII. Intern. Congr. Anim. Reprod., München (1972) 1143-1148.

SPENCER, J.R., TORRADO, T., SANCHEZ, R.S., VAUGHAN, E.D., Jr. und IMPERATO-MCGINLEY, J.: Effects of flutamide and finasteride on rat testicular descent. Endocrinology 129 (1991) 741-8.

STIGLER, J.: Analyse von Erbfehlern beim Schwein. Dissertation, LudwigMaximilian-Universität München (1990). 
STIGLER, J., DISTL, O., KRUFF, B. und KRÄUSSLICH, H.: Segregation analysis of hereditary defects in pigs. Züchtungskunde 63 (1991) 294305.

STIGLER, J., DISTL, O., KRUFF, B. und KRÄUSSLICH, H.: Zur Erblichkeit wirtschaftlich relevanter Missbildungen beim Schwein. Tierärztliche Umschau 47 (1992) 883-886.

STRATIL, A., PEELMAN, L., VAN POUCKE, M. und CEPICA, S.: A Hinfl PCRRFLP at the porcine leptin (LEP) gene. Anim Genet 28 (1997) 371-2.

TANYEL, F.C.: Obliteration of processus vaginalis: aberrations in the regulatory mechanism result in an inguinal hernia, hydrocele or undescended testis. Turk J Pediatr 46 Suppl (2004) 18-27.

TANYEL, F.C., DAGDEVIREN, A., MUFTUOGLU, S., GURSOY, M.H., YURUKER, S. und BUYUKPAMUKCU, N.: Inguinal hernia revisited through comparative evaluation of peritoneum, processus vaginalis, and sacs obtained from children with hernia, hydrocele, and undescended testis. J Pediatr Surg 34 (1999) 552-5.

TERADA, M., GOH, D.W., FARMER, P.J. und HUTSON, J.M.: Calcitonin generelated peptide receptors in the gubernaculum of normal rat and 2 models of cryptorchidism. J Urol 152 (1994) 759-62.

THALLER, G., DEMPFLE, L. und HOESCHELE, I.: Investigation of the inheritance of birth defects in swine by complex segregation analysis. J. Anim. Breed. Genet. 113 (1996) 77-92.

UIBELEISEN, A.: Isolierung, Charakterisierung und molekulargenetische Analyse des porcinen HoxA-10 Gens. Masterarbeit, Georg-AugustUniversität Göttingen (2001).

VOGELI, P., MEIJERINK, E., FRIES, R., NEUENSCHWANDER, S., VORLANDER, N., STRANZINGER, G. und BERTSCHINGER, H.U.: [A molecular test for the detection of E. coli F18 receptors: a breakthrough in the struggle against edema disease and post-weaning diarrhea in swine]. Schweiz Arch Tierheilkd 139 (1997) 479-84.

WALDMANN, K.-H. und WENDT, M.: Lehrbuch der Schweinekrankheiten. Paul Parey Verlag, Stuttgart, 4. Auflage (2001).

WARWICK, W.L.: A study of hernia in swine. Wisc. Agri. Exp. Stat. Res. Bull. 69 (1926) 1-27.

WAYNE, M.L. und MCINTYRE, L.M.: Combining mapping and arraying: An approach to candidate gene identification. Proc Natl Acad Sci U S A 99 (2002) 14903-6.

WEMHEUER, W.: persönliche Mitteilung. (08.10.2008).

WENSING, C.J.: Testicular descent in the rat and a comparison of this process in the rat with that in the pig. Anat Rec 214 (1986) 154-60.

WIESNER, E. und RIBBECK, R.: Lexikon der Veterinärmedizin. Enke Verlag Stuttgart, 4.Auflage (2000).

WIESNER, E. und WILLER, S.: Veterinärmedizinische Pathogenetik. VEB Gustav-Fischer-Verlag, Jena, 1. Auflage, (1974).

YAMAMOTO, F. und YAMAMOTO, M.: Molecular genetic basis of porcine histoblood group AO system. Blood 97 (2001) 3308-10.

ZDS Jahresbericht: Schweineproduktion 2007 in Deutschland. Ausgabe 2008.

ZIMMERMANN, S., STEDING, G., EMMEN, J.M., BRINKMANN, A.O., NAYERNIA, K., HOLSTEIN, A.F., ENGEL, W. und ADHAM, I.M.: 
Targeted disruption of the Insl3 gene causes bilateral cryptorchidism. Mol Endocrinol 13 (1999) 681-91. 


\title{
6 Publikationsliste und Kongressbeiträge
}

\author{
Publikationen \\ Die vorliegende Arbeit basiert auf den durch Fettdruck hervorgehobenen \\ Publikationen.
}

Germerodt M, Knorr C, Beck J, Droegemueller, C, Williams, JL, Habermann F, Fries R, Brenig B (2004): Characterisation and chromosome localisation of a processed pseudogene related to the bovine laminin receptor gene family. Cytogenet Genome Res, 107, 123-127

Beuermann C, Germerodt, M, Beck J, Brenig, B, Knorr C (2008): Chromosomal assignment of eight porcine genes involved in apoptosis. Anim Genet, 39: 330-331.

Germerodt M, Beuermann C, G.A. Rohrer, W.M. Snelling, B. Brenig and C. Knorr (2008): Characterization and linkage mapping of 15 porcine STSmarkers to fine map chromosomal regions associated with Hernia inguinalis/scrotalis. Anim Genet, 39:671-672

Germerodt M, Moser G, Crump R, Ding N, Huang LS, Xing Y, Pach S, Brenig B, Knorr C (2009): Associations of PGK2 and SOX9 variants with reproduction performance in Artificial Insemination (AI) boars (in Bearbeitung)

Knorr C, Bornemann-Kolatzki K, Beck J, Germerodt M, Täubert H, Harlizius B, Brenig B (2009): Approaching porcine hernia inguinalis/scrotalis (in Bearbeitung)

\section{Kongressbeiträge (Vorträge)}

M. Germerodt, C. Knorr, B. Brenig

Charakterisierung und Bedeutung von Genen der bovinen Laminin-RezeptorGenfamilie (B07)

GfT/DGfZ-Tagung Göttingen, 17.-18.09 2003

M. Germerodt, C. Beuermann, J. Beck, E. Schütz, G.A. Rohrer, B. Brenig,

C. Knorr

Approaching porcine Hernia inguinalis/scrotalis

$2^{\text {nd }}$ European Conference on Pig Genomics, Ljubljana, Slovenia, June 4-5, 2008; editors P. Dovc et al.; ISBN: 978-961-6379-12-0; pp. 49-50

M. Germerodt, C. Beuermann, J. Beck, E. Schütz, G.A. Rohrer, B. Brenig,

C. Knorr

Strategien zur Untersuchung angeborener Hodensack- und Leistenbrüche beim Schwein (B26)

GfT/DGfZ-Tagung Bonn, 17.-18.09. 2008 


\section{Danksagung}

Bedanken möchte ich mich bei Herrn Prof. Dr. Dr. Bertram Brenig für die Überlassung des Themas und die Betreuung meiner Dissertation.

Außerdem gilt mein besonderer Dank Herrn Prof. Dr. Christoph Knorr für die Betreuung meiner Arbeit, für seine Unterstützung und Hilfe, die konstruktive Kritik und sein immer offenes Ohr.

Außerdem möchte ich mich bei meinen Kollegen und Freunden am Institut für die gute Zusammenarbeit, das gute Arbeitsklima und die Unterstützung bedanken.

Herrn Dr. Helge Täubert danke ich für die statistischen Auswertungen.

Ein großes Dankeschön an meine Freunde, die mich während der Promotion unterstützt haben und mir auch zu späterer Stunde am Telefon noch Mut zugesprochen haben oder Formatierungsprobleme gelöst haben: Dörthe, Elke, Edith, Liz, Mone, Heiko, Ute und nicht zu vergessen „meine“ sieben Ostfriesen. Mein besonderer Dank gilt meiner Familie, die mich während des Studium und der Dissertation immer unterstützt hat und mir Mut zugesprochen hat, wenn es mal nicht so einfach war.

Zuletzt möchte ich mich bei dir bedanken Steffen, für deine Liebe und dafür dass du immer an mich geglaubt hast! 